\title{
Multi-organ point-of-care ultrasound for COVID-19 (PoCUS4COVID): international expert consensus
}

\begin{abstract}
Arif Hussain ${ }^{{ }^{*}+}$ (D), Gabriele Via ${ }^{2 \dagger}$, Lawrence Melniker ${ }^{3}$, Alberto Goffi ${ }^{4}$, Guido Tavazzi ${ }^{5,6}$, Luca Neri ${ }^{7}$, Tomas Villen ${ }^{8}$, Richard Hoppmann ${ }^{9}$, Francesco Mojoli ${ }^{10}$, Vicki Noble ${ }^{11}$, Laurent Zieleskiewicz ${ }^{12}$, Pablo Blanco ${ }^{13}$, Irene W. Y. Ma ${ }^{14}$, Mahathar Abd. Wahab ${ }^{15}$, Abdulmohsen Alsaawi ${ }^{16}$, Majid Al Salamah ${ }^{17}$, Martin Balik ${ }^{18}$, Diego Barca ${ }^{19}$, Karim Bendjelid ${ }^{20}$, Belaid Bouhemad ${ }^{21}$, Pablo Bravo-Figueroa ${ }^{22}$, Raoul Breitkreutz ${ }^{23}$, Juan Calderon ${ }^{24}$, Jim Connolly ${ }^{25}$, Roberto Copetti ${ }^{26}$, Francesco Corradi ${ }^{27}$, Anthony J. Dean ${ }^{28}$, André Denault ${ }^{29}$, Deepak Govil ${ }^{30}$, Carmela Graci ${ }^{31}$, Young-Rock Ha ${ }^{32}$, Laura Hurtado ${ }^{33}$, Toru Kameda ${ }^{34}$, Michael Lanspa ${ }^{35}$, Christian B. Laursen ${ }^{36}$, Francis Lee ${ }^{37}$, Rachel Liu ${ }^{38}$, Massimiliano Meineri ${ }^{39}$, Miguel Montorfano $^{40}$, Peiman Nazerian ${ }^{41}$,

Bret P. Nelson ${ }^{42}$, Aleksandar N. Neskovic ${ }^{43}$, Ramon Nogue ${ }^{44}$, Adi Osman ${ }^{45}$, José Pazeli ${ }^{46}$, Elmo Pereira-Junior ${ }^{47}$, Tomislav Petrovic ${ }^{48}$, Emanuele Pivetta ${ }^{49}$, Jan Poelaert ${ }^{50}$, Susanna Price ${ }^{51}$, Gregor Prosen ${ }^{52}$, Shalim Rodriguez ${ }^{53}$, Philippe Rola ${ }^{54}$, Colin Royse ${ }^{55,56}$, Yale Tung Chen ${ }^{57}$, Mike Wells ${ }^{58}$, Adrian Wong ${ }^{59}$, Wang Xiaoting ${ }^{60}$, Wang Zhen ${ }^{61}$ and Yaseen Arabi62
\end{abstract}

\begin{abstract}
COVID-19 has caused great devastation in the past year. Multi-organ point-of-care ultrasound (PoCUS) including lung ultrasound (LUS) and focused cardiac ultrasound (FoCUS) as a clinical adjunct has played a significant role in triaging, diagnosis and medical management of COVID-19 patients. The expert panel from 27 countries and 6 continents with considerable experience of direct application of PoCUS on COVID-19 patients presents evidence-based consensus using GRADE methodology for the quality of evidence and an expedited, modified-Delphi process for the strength of expert consensus. The use of ultrasound is suggested in many clinical situations related to respiratory, cardiovascular and thromboembolic aspects of COVID-19, comparing well with other imaging modalities. The limitations due to insufficient data are highlighted as opportunities for future research.
\end{abstract}

Keywords: COVID-19, SARS-CoV-2, Point-of-care ultrasound (PoCUS), Focused cardiac ultrasound (FoCUS), Lung ultrasound (LUS), Echocardiography

\section{Introduction}

Since the first reports from China [1], SARS-CoV-2 has caused considerable morbidity and mortality from COVID-19 globally [1]. Although respiratory signs and

\footnotetext{
${ }^{*}$ Correspondence: hussain_pscc@hotmail.com

${ }^{\dagger}$ Arif Hussain and Gabriele Via have contributed equally to this work

${ }^{1}$ Department of Cardiac Sciences, King Abdulaziz Medical City and King Abdullah International Medical Research Center, Riyadh, Saudi Arabia

Full list of author information is available at the end of the article symptoms are the most common manifestations, other systems may be involved [2]. Clinical presentations range from mild (80\%) to life-threatening (5\%), usually as acute respiratory distress syndrome (ARDS). Paucity of evidence, and urgency to adjust to evolving clinical scenarios have prompted adoption of approaches based on institutional experience [3], limited evidence, or extrapolation from other conditions $[4,5]$. original author(s) and the source, provide a link to the Creative Commons licence, and indicate if changes were made. The images or other third party material in this article are included in the article's Creative Commons licence, unless indicated otherwise in a credit line to the material. If material is not included in the article's Creative Commons licence and your intended use is not permitted by statutory regulation or exceeds the permitted use, you will need to obtain permission directly from the copyright holder. To view a copy of this licence, visit http://creativecommons.org/licenses/by/4.0/. The Creative Commons Public Domain Dedication waiver (http://creativeco mmons.org/publicdomain/zero/1.0/) applies to the data made available in this article, unless otherwise stated in a credit line to the data. 
Point-of-care ultrasound (PoCUS) is a rapid, bedside, goal-oriented, diagnostic test that is used to answer specific clinical questions [6]. These distinctive features are appealing and address concerns of environmental contamination and disinfection of larger devices such as chest X-ray (CXR) and computed tomography (CT). Thus, multi-organ PoCUS could enhance the management of COVID-19 (Fig. 1).

\section{Methods}

We searched Medline, Pubmed Central, Embase, Cochrane, Scopus and online pre-print databases from 01/01/2020 to 01/08/2020, and collected all English language publications on PoCUS in adult COVID-19 patients, using the MeSH query: [("lung" AND "ultrasound") OR "echocardiography" OR "Focused cardiac ultrasound" OR "point-of-care ultrasound" OR "venous ultrasound"] AND ["COVID-19" OR "SARS-CoV2"]. This systematic search strategy (Fig. 2) [Additional file 1A] identified 214 records.

The available evidence for PoCUS in COVID-19 was considered. Where such evidence was not available, nonCOVID-19 data were used. We then applied an expedited 2-round modified Delphi process to elicit a consensus from an expert panel [Additional file 1A], who voted on PICO statements in 9 distinct domains (Table 1) ] [Additional file $1 \mathrm{~B}]$ and approved the final recommendations. Consistent literature was GRADEd. Summary recommendations were generated based on voting results, literature evidence and experts' input presented with Level of Quality of Evidence (LQE: I, II-A, II-B, III) and Level of Agreement (Very Good, Good, Some, None) [Additional file 1C] . Lastly, we identified limitations of PoCUS and areas of future research.

\section{DOMAINS 1-Diagnosis of SARS-CoV-2 infection, 2-Triage/disposition and 3-Diagnosis of COVID-19 pneumonia}

COVID-19 almost invariably involves the respiratory system [2]. Approximately 5\% of patients require critical care and mechanical ventilation, usually due to viral pneumonia and/or ARDS [7]. The diagnosis of COVID19 pneumonia is challenging:

- Although CT has the best diagnostic yield [8], access is limited by patient volume, resources and risk of environmental contamination.

- Pre-existing conditions [9], and acute exacerbations of these diseases are common.

- Instability may preclude intra-hospital transportation.
- Delays or unreliability of reverse-transcriptase polymerase-chain-reaction (RT-PCR) results complicate infection control [10].

- Several algorithms/approaches developed for triage [11-20] are perceived as helpful, but remain unvalidated.

\section{Evidence}

LUS is more accurate than CXR for diagnosing respiratory conditions [21], including interstitial diseases [22], pneumonia [23] and COVID-19 pneumonia [24]. The diagnostic accuracy of addition of LUS outperforms standard emergency department tests for dyspnea [25, 26]. LUS can diagnose COVID-19 pneumonia in patients with normal vital signs [27] and distinguish viral and bacterial pneumonias [28].

LUS findings associated with COVID-19 pneumonia are reported to be similar to previously described viral pneumonias [12, 22]. Frequently observed are [Additional files 2-5]: heterogeneous B-lines clusters, separated or confluent (corresponding to ground glass opacities on $\mathrm{CT})$, large band-like longitudinal artifacts arising from normal pleural line (characterized as "light beam" [12]), pleural line irregularities, subpleural consolidations and areas with decreased lung sliding due to poor ventilation. Large consolidations with air bronchograms may be present, more commonly in patients requiring mechanical ventilation, possibly representing progression to ARDS or superimposed bacterial infection. At presentation, the distribution, although bilateral, is usually asymmetrical and patchy [29-31]. Lung involvement may be limited to dorsal/basal areas in milder COVID-19 pneumonia [32]. LUS shows good agreement with CT in recognizing lung pathology and its severity $[33,34]$ thus, identifying patients at higher risk of clinical deterioration, ICU admission, mechanical ventilation and mortality [34-36]. B-line count, consolidations and thickened pleural lines are associated with positive RT-PCR tests and clinical severity [37, 38]. Coupled with pretest probability, bilateral B-lines [single and/or confluent], irregular pleural line and subpleural consolidations increase the likelihood of diagnosing COVID-19 [39, 40], while non-specific, bilateral heterogeneous patterns [Additional file 6], combined with a typical clinical presentation, strongly suggest viral pneumonia. Conversely, if pre-test probability is low [41], a bilateral A-pattern on LUS may exclude COVID-19 pneumonia owing to its high negative predictive value for pneumonia $[12,30]$.

Multi-organ PoCUS yields a better diagnostic performance for causes of respiratory failure than LUS alone [42]. As a rapid, accurate diagnostic approach to acute dyspnea [43-45], it outperforms standard tests 


\section{POTENTIALLY USEFUL POCUS APPLICATIONS in COVID-19 PATIENTS}

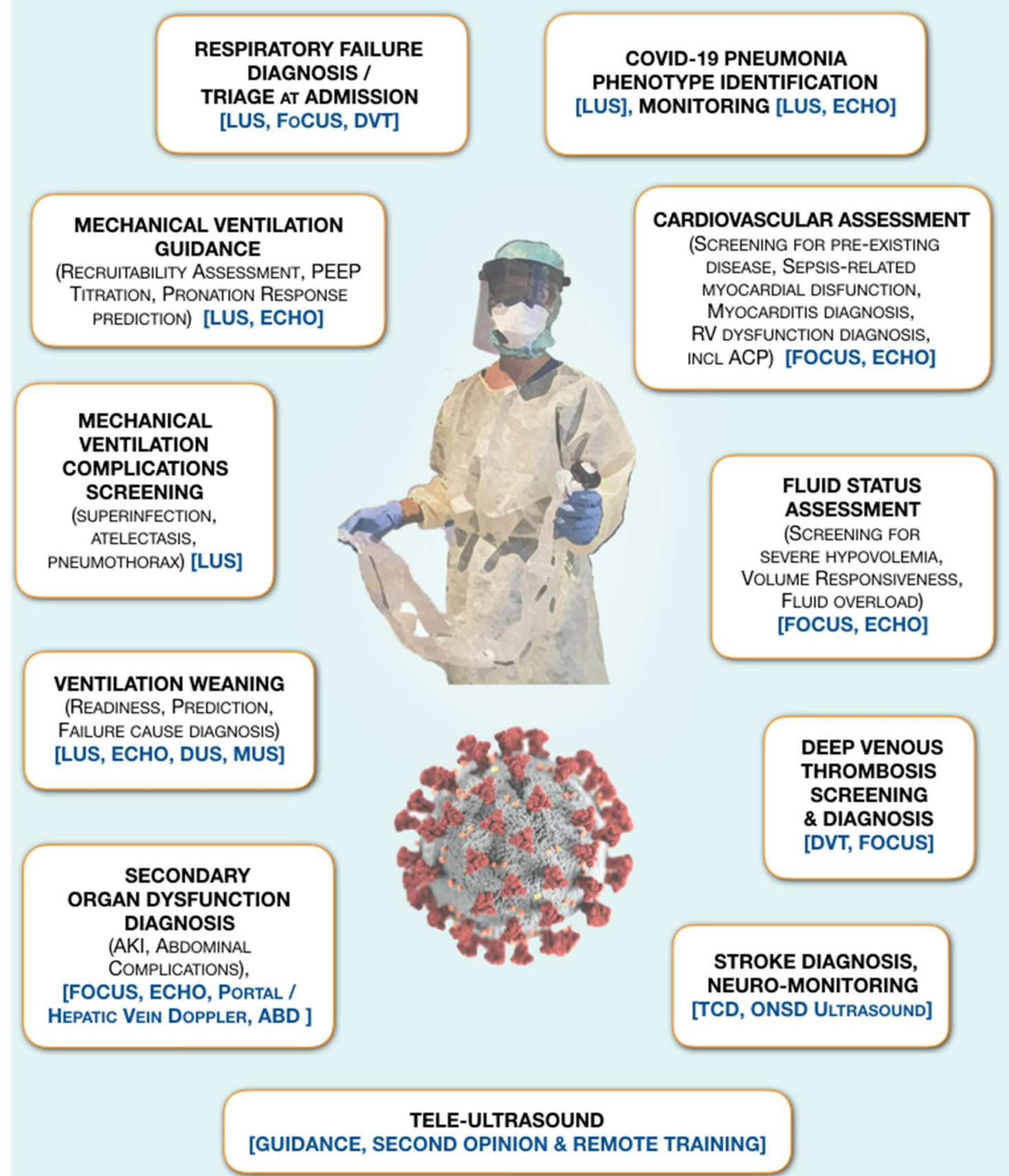

Fig. 1 Graphical synopsis of potentially useful applications of point-of-care ultrasound (PoCUS) in COVID-19 patients. ABD, abdominal ultrasound; ACP, acute cor pulmonale; AKI, acute kidney injury; DUS, diaphragmatic ultrasound; DVT, ultrasound for deep venous thrombosis screening; ECHO, echocardiography; FoCUS, focused cardiac ultrasound; LUS, lung ultrasound; MUS, parasternal intercostal muscles ultrasound; ONSD, optic nerve sheath diameter; PEEP, positive end expiratory pressure; PoCUS, point-of-care ultrasound; TCD, transcranial Doppler; VASC, ultrasound for venous and arterial access 


\section{Records Identified through Medline ( $\mathrm{N}=287$ )}

Records Identified through PMC ( $N=1561)$
Records Identified through Embase $(\mathrm{N}=485)$
Records Identified through Scopus $(\mathrm{N}=341$ )
Records Identified through

Cochrane $(\mathrm{N}=19)$

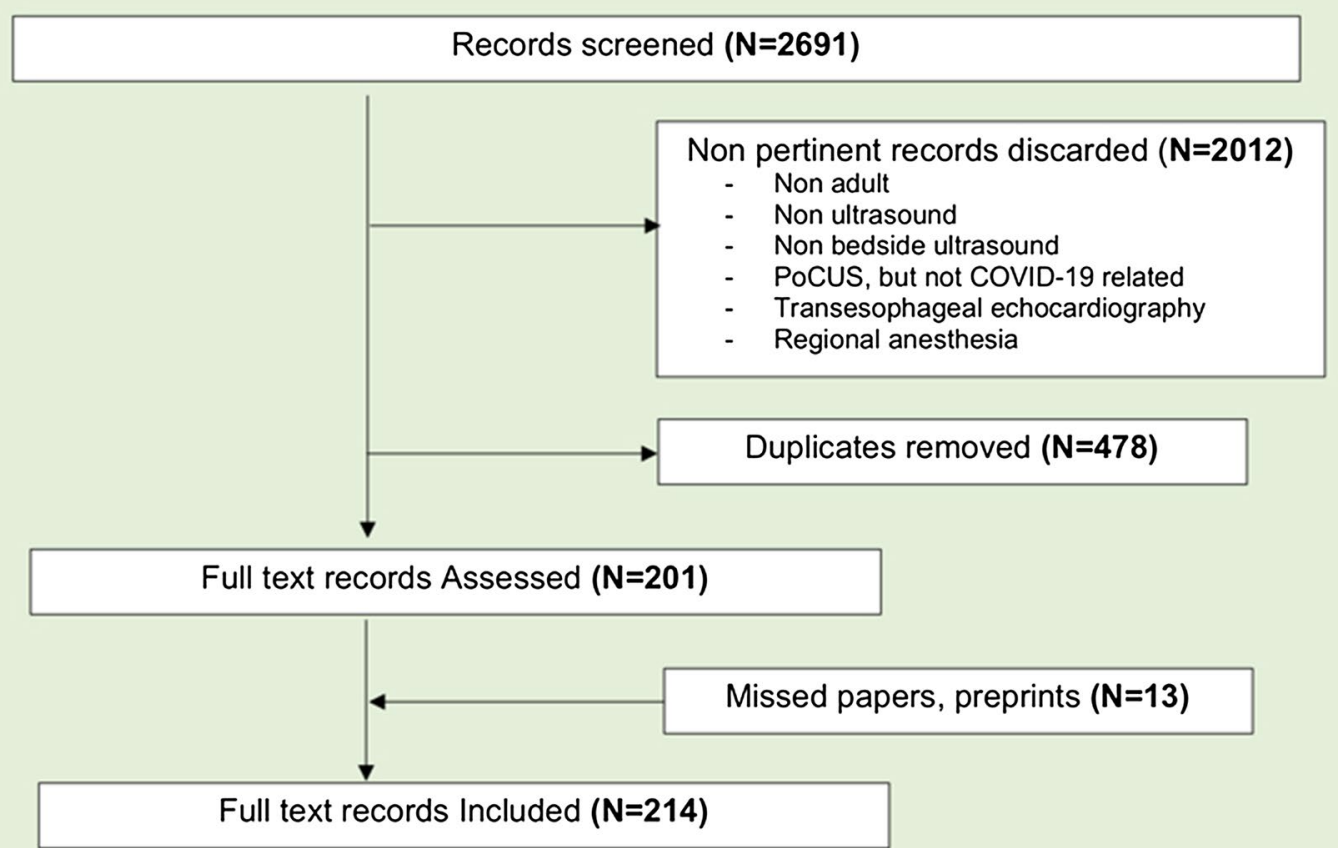

Fig. 2 Literature search strategy. A literature search of Pubmed, Pubmed Central, Embase, Scopus and Cochrane library databases was conducted by 2 independent researchers from 01/01/2020-01/08/2020 to identify all publications on point-of-care ultrasound in COVID-19 adult patients, using English language restriction, and the following MeSH query: (("lung" AND "ultrasound") OR "echocardiography" OR "Focused cardiac ultrasound" OR "point-of-care ultrasound" OR "venous ultrasound") AND ("COVID-19" OR "SARS-CoV2"). Non-pertinent findings were discarded. The references of relevant papers were hand-searched for missed papers. Duplicates were removed. An additional search of pre-print publications was made through ResearchGate, preprint online repositories and social medias

[26]. Similar results have been reported in undifferentiated shock [46]. PoCUS is recommended as a first-line diagnostic test for investigating respiratory failure and/ or hypotension [22, 47]. PoCUS may raise suspicions of falsely negative RT-PCR and/or alternate diagnoses [48]. Recognition of comorbidities (chronic RV or LV dysfunction) and COVID-19-associated complications (DVT and RV failure) may influence patient disposition, and PoCUS can change their management [40].

We present a conceptual framework for triage of respiratory failure [Additional file 7]. Without more data, triage protocols cannot be developed that are universally applicable.

\section{Recommendations}

1 We suggest using PoCUS, and especially LUS (presence of heterogeneous B-line clusters, pleural line irregularities, subpleural consolidations), and appropriately integrate the information with clinical assessment to diagnose COVID-19 pneumonia (LQE II-B, Very Good Agreement). 


\begin{tabular}{|c|c|}
\hline Domain 1 & PoCUS for Sars-Cov-2 infection diagnosis \\
\hline Domain 2 & PoCUS as a tool for triage/disposition \\
\hline Domain 3 & PoCUS for diagnosis of COVID-19 pneumonia \\
\hline Domain 4 & PoCUS for cardiovascular diagnosis \\
\hline Domain 5 & $\begin{array}{l}\text { PoCUS for screening and diagnosis of thromboembolic } \\
\text { disease }\end{array}$ \\
\hline Domain 6 & PoCUS and respiratory support strategies \\
\hline Domain 7 & PoCUS for management of fluid administration \\
\hline Domain 8 & PoCUS for monitoring of COVID-19 patients \\
\hline Domain 9 & $\begin{array}{l}\text { PoCUS and infection control, techniques, technology and } \\
\text { protocols }\end{array}$ \\
\hline
\end{tabular}

2 When CT-scan is not accessible or appropriate, we suggest using LUS to aid the diagnosis of COVID19 pneumonia in suspected cases (LQE II-B, Good Agreement).

3 In patients with high pre-test probability for COVID19 and LUS findings suggestive of pneumonia, a negative nasal/oropharyngeal RT-CR may not be used to exclude COVID-19, and LUS findings, further raising suspicion, should prompt repeat testing with better yield (LQE II-B, Good Agreement).

4 We do not recommend using PoCUS and LUS alone to rule out SARS-CoV-2 infection in suspected COVID-19 (LQE II-B, Good Agreement).

5 After thorough examination of all lung fields and intercostal spaces, a bilateral A-pattern suggests absence of pneumonia in suspected or confirmed SARS-CoV-2 infection (LQE III, Good Agreement).

6 We suggest multi-organ PoCUS integrated with other clinical information for triaging and risk stratification of suspected COVID-19 at initial presentation (LQE II-B, Good Agreement).

\section{Limitations and future research}

More data are required to establish the accuracy of LUS findings for the diagnosis of COVID-19 pneumonia versus other viral pneumonias. PoCUS use for risk stratification, outcome prediction, and its impact on management of COVID-19 needs study.

\section{DOMAIN 4-Cardiovascular diagnosis in COVID-19}

Numerous cardiovascular issues are associated with COVID-19:

- Patients with cardiovascular comorbidities seem to develop more severe COVID-19 [49].
- Up to $17 \%$ of hospitalized COVID-19 patients sustain acute cardiac injury (ACI) that increases mortality [50, 51-53]. Besides the inflammatory and direct cellular injury, other possible mechanisms for ACI include hypoxemia and result in oxygen supply/demand imbalance [54]. A close association of acute and fulminant myocarditis with COVID-19 is not established. However, if present, it will result in low output syndrome or cardio-circulatory collapse [55]. Though high-sensitivity troponin assays allow detection of myocardial injury, no cutoff values reliably distinguish myocardial infarction (MI) from other ACI [56]. Elevation of cardiac biomarkers, ECG changes, LV and RV dysfunction $[57,58]$ have been reported in myocarditis and AMI [55, 59].

- It is difficult to distinguish the effects of pneumonia from superimposed congestive heart failure [59].

- Respiratory acidosis, alveolar inflammatory edema and microvascular alterations may increase pulmonary vascular resistance [60], and positive pressure ventilation may further increase RV afterload, precipitating RV failure [61].

- Various cardiac manifestations [62] have been described, and some critically ill COVID-19 patients exhibit shock states [51].

\section{Evidence}

Echocardiography and FoCUS are established tools for diagnosing cardiovascular disease [47, 63, 64]. FoCUS can detect pre-existing cardiac disease [Additional file 8] and acute RV and/or LV dysfunction [47]. Echocardiography [65] and FoCUS are recommended by American and European Echocardiography societies as diagnostic/ monitoring tools in COVID-19 [66, 67]. FoCUS can guide decisions on coronary angiography [68] and inotropic/ mechanical circulatory support $[59,69,70]$. Overt symptoms of myocardial ischemia, raised cardiac biomarkers, ECG changes and new LV regional wall motion abnormalities should be carefully evaluated so that myocardial infarction [Additional file 9] diagnostic/therapeutic pathways are followed expediently [54, 67, 68]. Low voltage QRS complexes, myocardial hyper-echogenicity, diffuse hypokinesia or regional wall motion abnormalities suggest myocarditis [71] [Additional file 11]. Acute cor-pulmonale can occur in COVID-19 [58, 72], and FoCUS can detect RV dilatation, paradoxical septal motion and RV longitudinal dysfunction [47] [Additional file 10]. Thus, FoCUS/echocardiography together with clinical and biochemical indices can enhance management of cardiovascular compromise. 


\section{Recommendations}

7. We suggest FoCUS and/or echocardiography assessment in moderate-severe COVID-19 as it may change clinical management or provide information that could be lifesaving (LQE II-B, Very Good Agreement).

8 We suggest FoCUS and/or echocardiography for assessment of hemodynamic instability in moderate-severe COVID-19 (LQE II-B, Very Good Agreement).

9 We recommend FoCUS and echocardiography to diagnose RV and LV systolic dysfunction and cardiac tamponade as etiology of hemodynamic instability in COVID-19 (LQE II-B, Very Good Agreement).

10 We suggest using FoCUS/echocardiography to guide hemodynamic management in severe COVID-19 (LQE II-B, Very Good Agreement).

\section{Limitations and future research}

Whether subtypes of COVID-19 exist with more severe cardiovascular involvement and worse prognosis, requires investigation. Study of diastolic function may be of interest in COVID-19.

\section{DOMAIN 5-Screening and diagnosis of venous thromboembolic disease (VTE)}

The risk of VTE in COVID-19 is high:

- Due to high incidence of DVT [73, 74] [Additional file 13].

- Pulmonary embolism (PE) [75, 76] [Additional file 10] and clotting in renal replacement circuits [75] in COVID-19 ICU patients are early and late complications.

- COVID-19 is associated with immunothrombotic dysregulation [77]. This manifests with high D-dimer [78], high C-reactive protein levels, antiphospholipid antibodies [75] and sepsis-induced coagulopathy [79], and is likely to increase mortality [79].

- Screening for coagulopathy can risk stratify patients and may determine the need for anticoagulation [80]. However, higher D-dimer cutoffs may be needed to improve its specificity for DVT in COVID-19 [81].

- Whether DVT detection at hospital admission suggests more severe COVID-19 remains unknown.

- Despite standard thromboprophylaxis DVT is common in COVID-19 [81, 82].

\section{Evidence}

Ultrasound is the mainstay of DVT diagnosis [83]. Screening is advised, when feasible, in the general management of COVID-19 patients [84]. Many factors limit access to formal duplex venous sonography [85]. Although routine screening is not widely recommended [86], twice weekly ultrasound surveillance can detect DVT, avert PE and reduce mortality in ICU patients [87].

Lower extremity ultrasound is recommended in COVID-19 patients with unexplained RV dysfunction, unexplained/refractory hypoxemia, or in patients with suspected PE who are too unstable for intra-hospital transport [86].

\section{Recommendations}

11.Because critically ill COVID-19 patients have high risk for VTE, we suggest regular screening for DVT, including central vessels with catheters, independent of oxygenation and coagulation (LQE II-A, Very Good Agreement).

12 In moderate-severe COVID-19 with hemodynamic worsening or sudden instability, we suggest FoCUS for prompt investigation of acute cor-pulmonale (LQE II-B, Very Good Agreement).

13 In moderate-severe COVID-19, we suggest that echocardiographic indices of worsening RV function and/or increased pulmonary artery pressure may indicate PE (LQE II-A, Very Good Agreement).

\section{Limitations and future research}

DVT prevalence and its role in risk stratification in mild COVID-19 are not known. Correlation of DVT with different COVID-pneumonia phenotypes needs study.

\section{DOMAIN 6-PoCUS and respiratory support strategies [including mechanical ventilation]}

Phenotypes of COVID-19 pneumonia associated with similar degrees of hypoxemia but different lung weight, aerated volume and compliance have been described [88]. These range from "classic" ARDS (Phenotype-H) that responds to higher PEEP, to the better aerated low elastance (Phenotype-L) that often requires lower PEEP [89]. Future studies may clarify whether phenotyping COVID-19 pneumonia can guide respiratory support, mechanical ventilation settings, and minimize ventilator-induced lung injury [89].

"Classic" ARDS commonly involves dependent lung regions [90]; the same areas are typically involved in 
advanced COVID-19 pneumonia [89, 91]. Localizing consolidated lung is important to maximize benefit from prone positioning. Prone positioning is preferable when dorsal consolidation is severe with spared ventral zones [92]. Prone positioning in non-intubated patients may rapidly improve oxygenation [93, 94].

\section{Evidence}

Like CT, LUS accurately characterizes regional lung pathology and identifies ARDS in COVID-19 pneumonia $[33,34,40,95]$. LUS may discriminate mild-moderate from moderate-severe aeration loss, distinguishing different ARDS phenotypes [96] (Fig. 3).

Importantly, LUS may facilitate identification of patients with greater hypoxemia than expected for their alveolar lung injury (Fig. 3), in whom the pathophysiology may involve deranged perfusion (PE, micro-thrombosis, loss of pulmonary vasoconstriction, extrapulmonary shunt).

Global LUS score is strongly associated with lung tissue density/aeration measured with CT [97]. Using LUS to guide mechanical ventilation has been recommended [98] (Fig. 4). However, recruitment demonstrated by LUS correlates with recruitment estimated by pressure-volume curves [99], but not CT [97]. Although LUS may not predict oxygenation response to prone positioning, it does predict re-aeration of dorsal zones [100] (Fig. 5). LUS findings also correlate with extravascular lung water in ARDS $[101,102]$ and can monitor changes in aeration [103]. This has also been suggested in COVID-19 [104-106].

\section{Recommendations}

14. We suggest multi-organ PoCUS including LUS over no imaging to guide respiratory support in COVID19 with respiratory failure (i.e. ventilation, prone positioning, PEEP, recruitment maneuvers) (LQE II-A, Good Agreement).

15 In addition to standard respiratory monitoring, we suggest LUS over CXR and equally to CT, to guide clinical decisions on respiratory support in COVID19 with respiratory failure (LQE II-B, Good Agreement).

16 We suggest multi-organ PoCUS over LUS alone for decisions about respiratory support in COVID-19 with respiratory failure (LQE II-B, Good Agreement).

\section{Limitations and future research}

The benefit of LUS in ventilated COVID-19 patients is only theoretical. Studies to predict response to prone positioning, PEEP titration and other interventions are awaited. Role of LUS to decide invasive mechanical ventilation is unknown.

\section{DOMAIN 7-Management of fluid administration in COVID-19 patients}

Fluid management is fundamentally important and often challenging in critically ill patients [107]. In COVID-19 patients, fluid overload can exacerbate lung dysfunction. Recent recommendations stress the need for conservative fluid strategies [4].

\section{Evidence}

A large international survey found that PoCUS was the most frequently used approach to assess fluid responsiveness in critically ill COVID-19 patients [108]. While FoCUS can detect early signs of severe central hypovolemia [47] [Additional file 12], interpretation of inferior and superior vena cava collapsibility/distensibility indices is difficult when a variety of ventilation modalities are employed [18, 109]. Transesophageal echocardiography has inherent risks and limitations related to manpower and infection control [110].

Dynamic indices based on stroke volume variation, passive leg raising and mini-bolus administration techniques are good predictors of fluid responsiveness $[111,112]$ and can be assessed with transthoracic echocardiography.

In non-COVID-19 pneumonia patients, LUS has been shown to provide information on fluid tolerance and detect the consequences on the lung of overzealous fluid

\footnotetext{
(See figure on next page.)

Fig. 3 Examples of lung ultrasound cumulative patterns of patients presenting with a similar degree of hypoxemia, but very different degree of aeration and respiratory mechanics characteristics, and recalling the recently proposed COVID-19 pneumonia phenotypes [89]. Patient on upper panel presents a nearly normal respiratory system compliance and LUS evidence of a milder lung involvement, reflected in a total LUS score of 11. This suggests a lung condition matching which has been recently described as "Phenotype L," based on CT findings, and characterized by low lung elastance and low ventilation/perfusion ratio (explaining the severe hypoxia). Based on this imaging and on respiratory mechanics findings, final PEEP was set at $10 \mathrm{~cm} \mathrm{H}_{2} \mathrm{O}$. Upper panel shows LUS evidence of a more diffuse and severe diffuse sonographic interstitial syndrome (cause of the shunt and the severe hypoxia), yielding a total LUS score of 27. Respiratory mechanics characteristics recall what has been described as "Phenotype H" (COVID-19 pneumonia: high lung elastance, high right-to-left shunt). Based on this imaging and on respiratory mechanics findings, PEEP was set at $14 \mathrm{~cm} \mathrm{H}_{2} \mathrm{O}$ after a stepwise recruiting maneuver. LUS, lung ultrasound
} 


\section{COVID-19 PNEUMONIA LUS, consistent with "Phenotype L"}

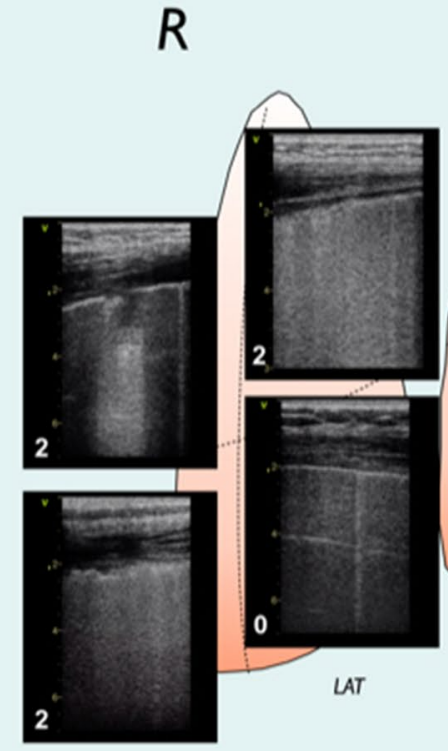

POST

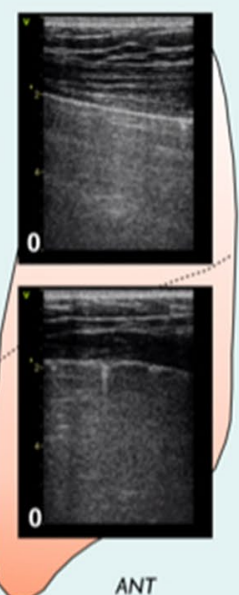

LUS Score $=11$

Male, $64 \mathrm{y}$, hypertension Crs 44 ml/cmH20, P/F 105

(final PEEP set at $10 \mathrm{cmH} 20$ )

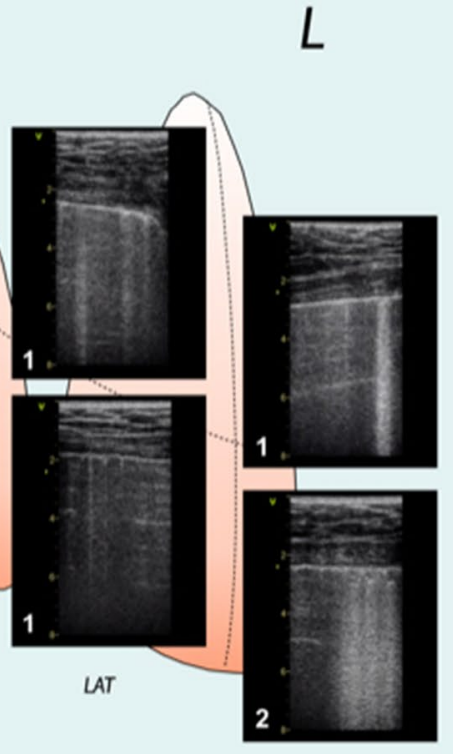

POST

\section{COVID-19 PNEUMONIA LUS, consistent with "Phenotype H"}

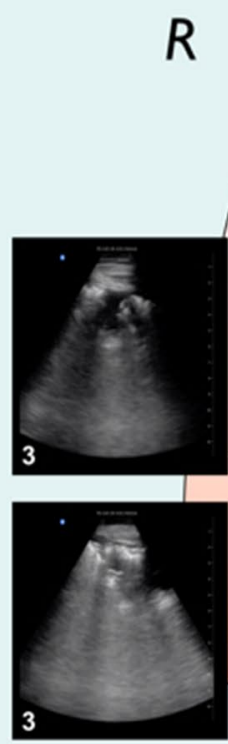

POST
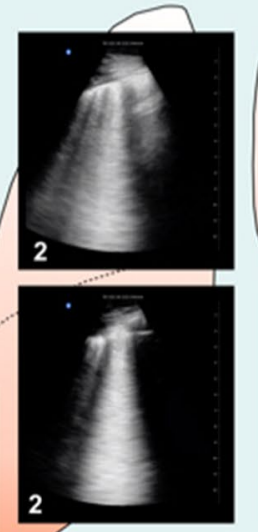

ANT

LUS Score $=27$

Male, $74 \mathrm{y}$, hypertension, $\mathrm{CAD}$, chronic kidney failure Crs $28 \mathrm{ml} / \mathrm{cmH} 20$, P/F 82,

(final PEEP set at $14 \mathrm{cmH} 20$ )
$L$

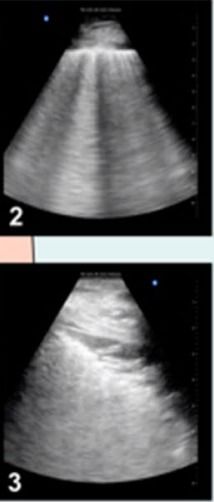

POST 


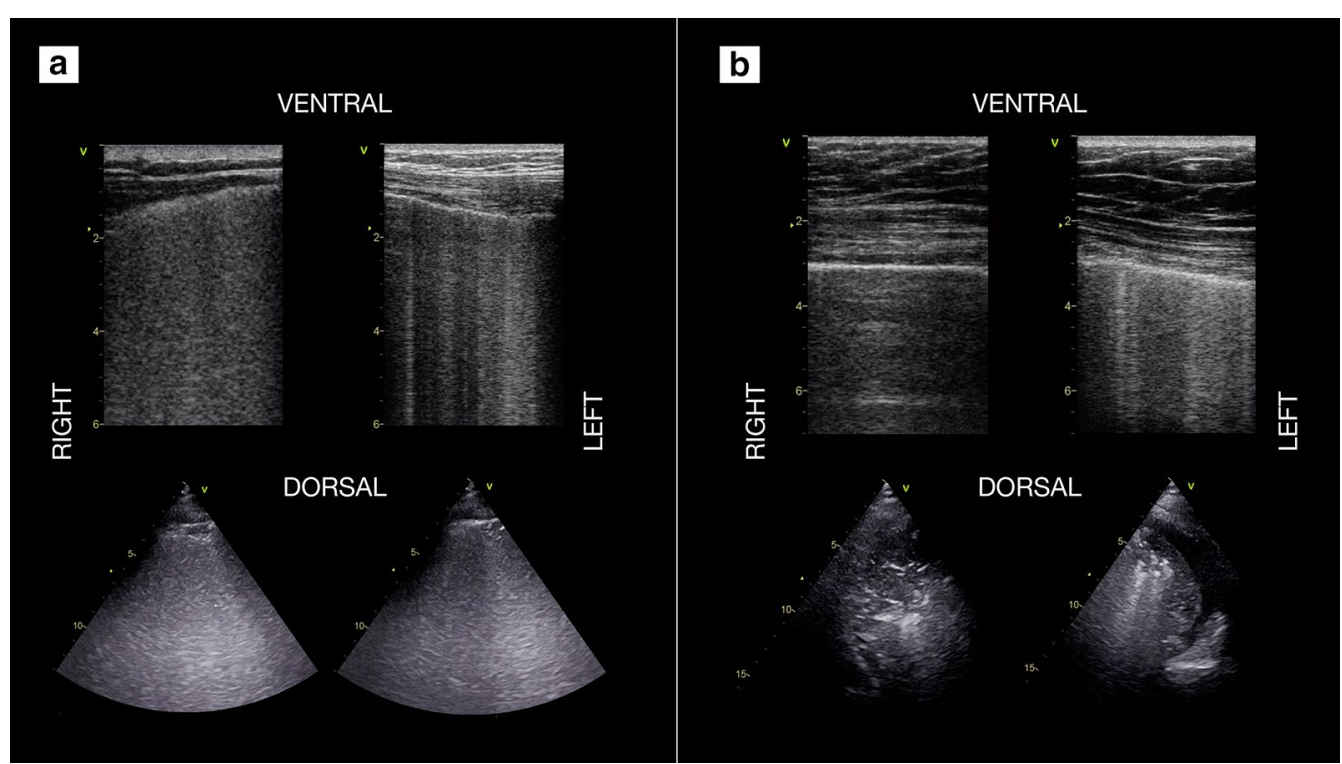

Fig. 4 Use of lung ultrasound to monitor lung aeration and guide ventilatory management in 2 COVID-19 patients. a COVID-19 patient on day 2 after intubation and ICU admission, initially with PEEP $12 \mathrm{cmH}_{2} \mathrm{O}$ : diffuse bilateral B-pattern with crowded, coalescent B-lines ("white lung appearance") is visible, consistent with a sonographic interstitial syndrome and severe loss of aeration/increase of extravascular lung water. Based on these findings and on respiratory mechanics, a stepwise recruitment maneuver with a final PEEP set at $15 \mathrm{cmH}_{2} \mathrm{O}$ was performed, with improvement in gas exchange. b A different COVID-19 patient on day 4; PEEP set at $14 \mathrm{cmH}_{2} \mathrm{O}$ : in comparison with previous patient, less B-lines are visible in ventral scans, with asymmetric distribution (more on the left scan); dorsal areas show lung consolidations, larger on the right side, with air bronchograms (dynamic at live scan). A pronation trial was successful, yielding immediate improvement in gas exchange and subsequent re-aeration of dorsal areas. (Ventral scans are taken with a linear, high frequency probe, dorsal ones with a phased array low-frequency one)

resuscitation [113, 114]. Resolution of B-lines during hemodialysis has been described [115] and also observed in COVID-19 patients [116, 117].

\section{Recommendations}

17.We suggest FoCUS to screen for severe hypovolemia in moderate-severe COVID-19 at presentation, while Doppler-based fluid-responsiveness indices may be used for subsequent management (LQE II-A, Very Good Agreement).

18 We suggest that LUS alone is not sufficient as a screening tool for pulmonary congestion in moderate-severe COVID-19 (LQE III, Very Good Agreement).

19 We suggest that LUS alone is not sufficient to judge the appropriateness of fluid administration in moderate-severe COVID-19 (LQE II-B, Very Good Agreement).

20 In moderate-severe COVID-19, we suggest multiorgan PoCUS to monitor efficacy of fluid removal, by not only LUS findings of reduction of B-pattern areas, but also echocardiographic signs of resolution of volume overload and decreasing LV filling pressures (LQE II-B, Very Good Agreement).

\section{Limitations and future research}

In COVID-19 pneumonia, the severity of the bilateral interstitial manifestations may either be due to variations in the inflammatory condition of the lung or changes due to pulmonary congestion. Simplified PoCUS-guided fluid management could be beneficial in resource-limited settings and needs further studies.

\section{DOMAIN 8-Monitoring patients with COVID-19 PoCUS FOR RESPIRATORY MONITORING:} COVID-19 pneumonia is characterized by a wide spectrum of clinical presentations, from mild-moderate hypoxia to severe manifestations requiring life-sustaining measures [118]. In situations where large numbers of patients are admitted to areas with limited monitoring and staffing, disease progression may go unrecognized. Moreover, rapid progression to respiratory arrest has been reported [119]. Severe COVID-19 pneumonia is characterized by severe respiratory failure [120], but not necessarily as ARDS.

\section{Evidence}

Evolution of LUS findings and their quantification using scoring systems are effective in monitoring progression 


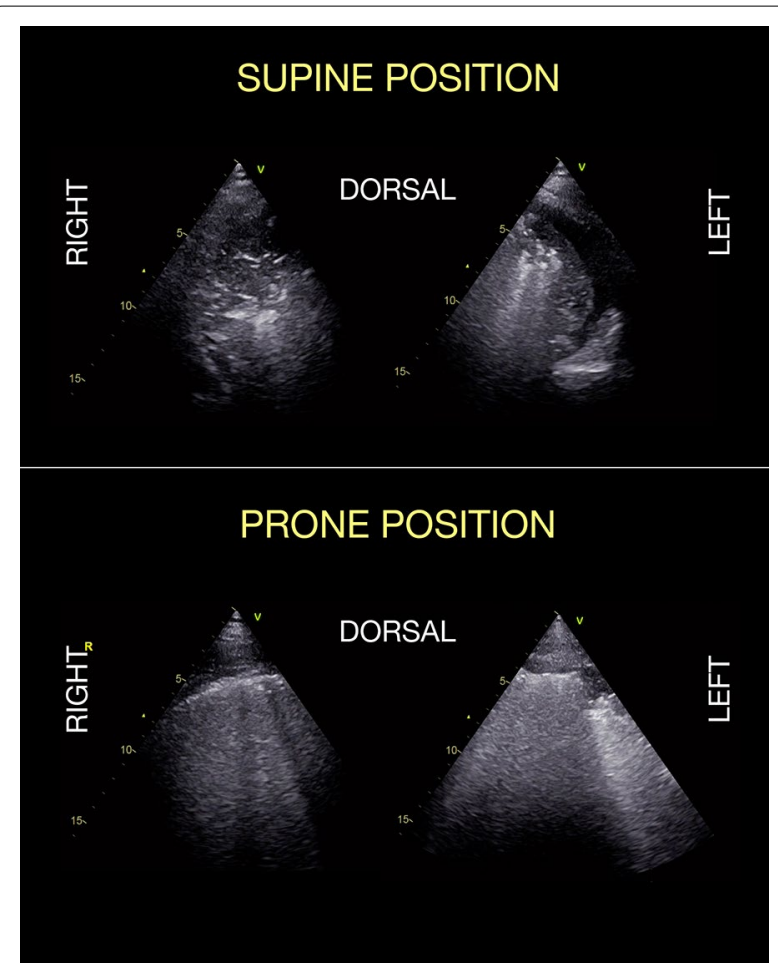

Fig. 5 Lung ultrasound to monitor adequacy of re-aeration of dorsal areas upon pronation and recruitment maneuvers in a COVID-19 patient. Same patient of Fig. 2B, before (upper panels) and after (lower panels) pronation and a series of stepwise recruitment maneuvers up to PEEP $26 \mathrm{cmH}_{2} \mathrm{O}$, and final PEEP setting at $16 \mathrm{cmH}_{2} \mathrm{O}$

or resolution of lung injury, especially in terms of variations in aeration and extravascular water content [22, $98,103,121,122]$. LUS is very sensitive, but is not specific enough to identify all causes of respiratory deterioration [22]. A comprehensive semi-quantitative LUS approach [97] can assess severity of lung injury and distribution patterns.

In patients with COVID-19 pneumonia, progression of LUS findings has been correlated with clinical and radiological deterioration. Thus, it can accurately monitor the evolution throughout its spectrum of severity, from mechanically ventilated $[104,105,123]$ or veno-venousECMO patients [106], to milder cases [124,125, 126]. LUS has helped in identifying superimposed bacterial infections [127], and the response to antibiotic treatment [128]. LUS Monitoring has reduced use of CT and CXR in critically ill and COVID-19 populations $[129,130]$.

\section{Recommendations}

21. We suggest serial LUS for respiratory monitoring in moderate-severe COVID-19 (LQE II-B, Very Good Agreement).
22 We suggest multi-organ PoCUS integrated with other clinical and biochemical variables, in preference to CXR for investigation of respiratory deterioration in moderate-severe COVID-19 (LQE II-A, Very Good Agreement).

23 We suggest multi-organ PoCUS over LUS alone to detect respiratory deterioration and guide treatment in moderate-severe COVID-19 (LQE II-B, Very Good Agreement).

\section{Limitations and future research}

LUS has limitations and requires further research in early identification of patients who are more likely to progress to severe respiratory failure with inflammation, their pneumonia phenotype, and separate them from those with congestion.

DETECTION OF MECHANICAL VENTILATIONRELATED COMPLICATIONS: Approximately 2.5\% of all COVID-19 patients [118] and up $88 \%$ of those admitted to ICU [9] require invasive mechanical ventilation, which may often last for weeks. The diagnosis of complications associated with prolonged ventilation requires imaging that may be limited due to risk of exposure to healthcare workers and environmental contamination. Thus, PoCUS, performed at the beside by the treating physician, may provide an accurate alternative.

\section{Evidence}

Pneumothorax. LUS has significantly higher sensitivity than CXR for the diagnosis of pneumothorax [79\% versus $40 \%$ ], whereas specificity is equally excellent [131]. However, most of these data are from trauma and postprocedural studies and may overestimate diagnostic performance of LUS in COVID-19. The negative predictive value of LUS for pneumothorax is approximately $100 \%$ (if pleural sliding, lung pulse and $\mathrm{B}$ or $\mathrm{C}$ patterns are observed) [132].

Ventilator-associated pneumonia. In the appropriate context, large consolidations not responsive to recruitment maneuvers or suction [133] are highly suggestive of secondary bacterial infection $[127,134]$.

Diaphragmatic dysfunction, and weaning failure from mechanical ventilation. Ventilation-induced diaphragmatic injury can be reliably assessed with ultrasound [135]. Combining LUS score with the evaluation of LV and diaphragm function may improve the success of weaning trials [136-139]. Assessment of parasternal intercostal muscles thickening fraction seems promising for predicting weaning failure [140]. Detection and treatment of unresolved pulmonary conditions can facilitate weaning $[141,142]$. 
Acute cor-pulmonale. The effects of mechanical ventilation on RV function have been well-described. Acute cor-pulmonale becomes an important factor to be considered in the ventilation strategy $[61,143]$.

\section{Recommendations}

24. We suggest a prompt assessment of clinical deterioration with LUS for a timely and accurate bedside diagnosis of pneumothorax in severe COVID-19 (LQE II-B, Very Good Agreement).

25 We suggest LUS for early identification of ventilatorassociated pneumonia in severe COVID-19 (LQE II-B, Very Good Agreement).

26 We suggest multi-organ PoCUS over CXR and CT to assess readiness for weaning, predict success and diagnose the cause(s) of weaning failure in COVID19 (LQE II-B, Very Good Agreement).

\section{Limitations and future research}

The safety and cost-saving impact of LUS in diagnosing complications of mechanical ventilation is yet to be demonstrated. A decision process based on PoCUS for tracheal extubation vs. tracheostomy mandates validation.

\section{PoCUS FOR HEMODYNAMIC MONITORING Evidence}

FoCUS and echocardiography are recommended for hemodynamic monitoring in critical care [47, 63, 64]. A recent survey found that ultrasound is the most frequently used monitoring tool to assess cardiac output and pulmonary artery pressures in critical COVID-19 patients [108].

\section{Recommendations}

27.We suggest FoCUS and/or echocardiography for hemodynamic monitoring in moderate-severe COVID-19 (LQE II-A, Very Good Agreement).

28 We suggest integrating PoCUS-derived information with data from other devices used for hemodynamic monitoring in severe COVID-19 (LQE II-B, Very Good Agreement).

\section{Limitations and future research}

Validated PoCUS-driven hemodynamic management protocols in COVID-19 are needed.
PoCUS FOR MONITORING OF OTHER ORGANS: Many critically ill COVID-19 patients develop secondary organ dysfunction, including acute kidney injury (AKI), liver injury, rhabdomyolysis and gastrointestinal complications [118, 144]. Hemodynamic factors and viral tropism for tubular cells may contribute to AKI [145]. Gastrointestinal complications may result from sepsis, deranged hemodynamics, or microvascular thrombosis [75]. Neurological complications are also not infrequent in COVID-19 [146].

\section{Evidence}

PoCUS can exclude post- and pre-renal causes of AKI (by assessing volume status and hemodynamics). It can detect systemic and renal venous congestion, important factors in AKI [147, 148], acute gastrointestinal complications $[149,150]$ including cholestasis and bowel ischemia in COVID-19 patients [151]. The use of PoCUS for the diagnosis and management of neurological conditions is acknowledged [152] and may be applicable in COVID-19.

\section{Recommendations}

29. We suggest PoCUS assessment for pre-renal causes of AKI, including hemodynamics and venous congestion in COVID-19 (LQE II-B, Very Good Agreement).

\section{Limitations and future research}

Expertise and data on PoCUS applications to detect organ dysfunction in COVID-19 especially AKI and acute abdomen are limited and need further study.

\section{DOMAIN 9-Infection control, PoCUS technique, technology, and protocols}

In the context of COVID-19:

- Interest in PoCUS has increased.

- Choice of machines is limited.

- Infection transmission to operators and environmental viral dissemination are serious concerns that may impact the quality of ultrasound examination and the choice of equipment.

- A systematic scanning approach is required to avoid missing or misinterpreting important findings.

\section{Evidence}

Laptop/tablet/pocket-sized machines provide reasonable compromise between portability and capability [153] (Fig. 6). Multi-frequency probes may be preferable to visualize both deep and superficial structures. While a 


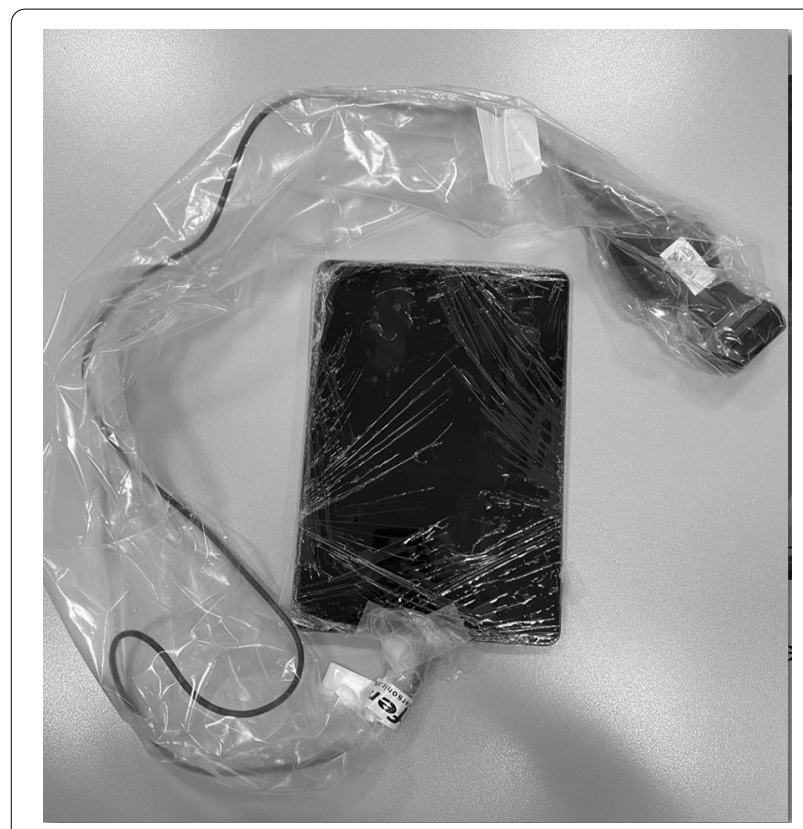

Fig. 6 Example of highly portable ultrasound device covered for use on COVID-19 patients. The IPAD, with which the device works, is tightly enveloped in plastic film wrap, while the probe is covered with a dedicated sheath (normally used for sterile ultrasound-guided procedures). Donning and doffing the device requires assistance and involves stepwise uncovering, with multiple steps of disinfection before and after removing the covering. Use of the device is restricted to the COVID-19 unit

single phased-array probe is suitable for FoCUS and LUS [154], a convex probe has been recommended by some experts [22]. Topographic zones and scanning techniques require standardization $[12,22,30]$. There is also a growing interest in telemedicine technology including robotic examinations [155] for remote guidance of minimally trained operators [156, 157] [Additional file 14].

To protect healthcare workers and patients, stringent infection control practices are crucial. Available guidance deals with environmental transmission and spread to personnel [158]. Recommendations on disinfectants [159] and information on SARS-CoV-2 survival on fomites [160] are also available.

\section{Recommendations}

30. We suggest using laptop/tablet/pocket-sized devices with adequate imaging capabilities that are easier to protect from viral contamination in COVID-19 (LQE IIB, Good Agreement).

31. For diagnostic accuracy, quality control and obtaining second opinions, we suggest performance of standardized PoCUS examinations in COVID-19 (LQE II-B, Good Agreement).
32. We recommend reporting PoCUS studies and recording, storage and archiving of diagnostic images and cine-clips (LQE II-B, Good Agreement).

33. We suggest using tele-ultrasound for remote guidance and consultations in COVID-19. Simple audio-visual communication devices (e.g. smartphones) can facilitate this (LQE II-B, Good Agreement).

34. We suggest PoCUS over CXR and CT, where appropriate, to reduce environmental spread of infection and risk of infection to healthcare workers in COVID-19 (LQE IIA, Good Agreement).

35. We recommend strict adherence to manufacturers' guidance for cleaning and disinfection of equipment used for COVID-19 (LQE II-A, Good Agreement).

36. We suggest brief and targeted ultrasound examinations to minimize cross-infection in COVID-19 (LQE II-B, Good Agreement).

\section{Limitations and future research}

Information on quality, safety, remote mentoring/monitoring and archiving in COVID-19 is limited. Evidence for safety and efficacy of different disinfectants and methods of cleaning contaminated equipment is needed to make robust infection control policies.

\section{Conclusion}

This consensus document based on the available evidence and expert opinion should encourage the use of PoCUS to improve patient outcomes during the current pandemic and development of meaningful protocols and practices to overcome COVID-19 and prepare for future challenges.

\section{Supplementary information}

is available for this paper at https://doi.org/10.1186/s13054-020-03369-5.

Additonal file 1A. Panel Composition, Literature search

Additional file 1B. Consensus Methodology

Additional file 1C. Consensus Results and Summary Recommendations

Additional file 2. (Video 1) Lung ultrasound (LUS) findings in COVID-19 Pneumonia. Clusters of B-lines. These usually have a patchy distribution

Additional file 3. (Video 2) Lung ultrasound (LUS) findings in COVID-19 Pneumonia. Longitudinal bright, band-like, large artifacts

Additional file 4. (Video 3) Lung ultrasound findings (LUS) in COVID-19 Pneumonia. Subpleural consolidations and spared areas

Additional file 5. (Video 4) Lung ultrasound (LUS) findings in COVID-19 Pneumonia. Lung consolidations in dorsal areas

Additional file 6. (Video 5). Cumulative lung ultrasound pattern in a patient with COVID-19 pneumonia. The exam was performed considering 
3 regions per hemithorax (anterior, lateral and a posterior, with the sternum, the anterior axillary line and the posterior axillary line as landmarks) and an upper and a lower quadrant for each one of them. The resulting 6 areas per hemithorax are labelled with numbers from 1 to 6 , and with $L$ for left side and $\mathrm{R}$ for the right side

Additional file 7. PoCUS-empowered triage in respiratory failure during COVID-19 Pandemic. Conceptual framework of point-of-care ultrasound (PoCUS) use for the triage of dyspneic and/or hypoxemic patients, during the SARS-CoV-2 pandemic: the diagram does not represent an algorithm but rather a framework for potentially developing protocols according to local/institutional clinical practices, policies and regulations. It does not either provide a list of conclusive diagnosis or specific treatments, but suggests how to integrate at best PoCUS in the workflow of this specific setting

Additional file 8. (Video 6). Focused cardiac ultrasound (FoCUS) findings in a patient with COVID-19 Pneumonia and pre-existing cardiac disease. First panel shows a videoclip with findings consistent with chronic right ventricular dysfunction. Second panel shows videoclips with evidence of chronic left ventricular failure

Additional file 9. (Video 7). Focused cardiac ultrasound (FoCUS) findings in a patient with COVID-19 pneumonia and acute myocardial infarction.

Additional file 10. (Video 8). Focused Cardiac Ultrasound (FoCUS) findings in a patient with COVID-19 Pneumonia and acute cor pulmonale, due to both mechanical ventilation and submassive pulmonary embolism.

Additional file 11. (Video 9). Focused cardiac ultrasound (FoCUS) findings in a patient with COVID-19 pneumonia and myocarditis.

Additional file 12. (Video 10) Focused cardiac ultrasound (FoCUS) findings in a patient with COVID-19 pneumonia and severe hypovolemia.

Additional file 13. (Video 11). Focused cardiac ultrasound (FoCUS) findings in a patient with COVID-19 pneumonia and diffuse deep venous thrombosis. (Courtesy of Dr. Scopigni Francesca)

Additional file 14. (Video 12). Remote guidance with tele-ultrasound in the COVID-ICU. Operators within the isolation room perform lung and cardiac ultrasound exam in a COVID-19 pneumonia patient, with guidance and second opinion from a colleague in the non-COVID zone of the hospital. Guidance is provided verbally and with remote control of the ultrasound settings. (Courtesy of Dr. Bruno Capelli)

\section{Abbreviations}

ACI: Acute cardiac injury; ARDS: Acute respiratory distress syndrome; AKI: Acute kidney injury; COVID-19: Corona virus disease 19; CT: Computerized tomography; CXR: Chest radiography; DVT: Deep venous thrombosis; ECG: Electro-cardiogram; FoCUS: Focused cardiac ultrasound; ICU: Intensive care unit; LQE: Level of quality of evidence; LUS: Lung ultrasound; LV: Left ventricle; PE: Pulmonary embolism; PEEP: Positive end expiratory pressure; PICO: Patient intervention comparator outcome; PLR: Passive leg raising; PoCUS: Point-ofcare ultrasound; RT-PCR: Reverse-transcriptase polymerase-chain-reaction; RV: Right ventricle; SARS-CoV-2: Severe acute respiratory syndrome corona virus-2; SV: Stroke volume variation; TAPSE: Tricuspid annular plane systolic excursion; VTE: Venous thromboembolic disease.

\section{Acknowledgements}

The authors wish to acknowledge Mr. Steve Wilson, Medical Librarian, University of South Carolina School of Medicine, Columbia, SC, USA, for his valuable assistance with the online survey for the Deplhi process and Dr Rajendram Rajkumar, King Abdulaziz Medical City, Riyadh, for assisting with editing of the manuscript.

\section{Authors' contributions}

AH and GV contributed equally as authors in conceiving the contents, gathering the relevant material, preparing the manuscript and chairing the steering committee of the process, LM GRADEd the evidence and supervised the Delphi consensus process as methodologist and reviewed the manuscript, AG conceived the evidence presentation and edited, GT contributed to the cardiovascular and hematological sections, LN contributed to concepts of triaging, TV contributed to LUS, FC and FM contributed to the ventilation section, $\mathrm{RH}$ and VN contributed to the manuscript, and YA conceived the idea of this work, provided guidance and edited the manuscript. All the authors participated in the Delphi process, provided input for drafting recommendations and reviewed the manuscript.

\section{Funding}

There were no financial disclosures specific to this work*.

\section{Availability of data and materials}

The data and other material can be made available to the Journal.

\section{Ethics approval and consent to participate}

There was no ethics approval required or applicable for this work.

\section{Consent for publication}

No material has been borrowed/reproduced from any other authors or publications.

\section{Competing interests}

Except for the following authors, none have declared any disclosures with respect to the present work: A Hussain: Currently serving President of WINFOCUS_G Tavazzi: Received fees for lectures from GE Healthcare unrelated to this work—R Hoppmann: EchoNous Advisory Board—F Mojoli: Received fees for lectures from Hamilton Medical, GE Healthcare, Seda Spa and institutional relationship between University of Pavia and Hamilton Medical_ G Via: eMedical Academy co-founder-B Nelson: Echonous and DiA Advisory Board.

\section{Author details}

${ }^{1}$ Department of Cardiac Sciences, King Abdulaziz Medical City and King Abdullah International Medical Research Center, Riyadh, Saudi Arabia. ${ }^{2}$ Cardiac Anesthesia and Intensive Care, Cardiocentro Ticino, Lugano, Switzerland. ${ }^{3}$ New York Presbyterian Brooklyn Methodist Hospital, New York, NY, USA. ${ }^{4}$ Department of Medicine and Interdepartmental Division of Critical Care Medicine, University of Toronto, Toronto, Canada. ${ }^{5}$ Department of Clinical-Surgical, Diagnostic and Paediatric Sciences, Unit of Anaesthesia and Intensive Care, University of Pavia, Pavia, Italy. ${ }^{6}$ Anaesthesia and Intensive Care, Fondazione Istituto Di Ricovero E Cura a Carattere Scientifico, Policlinico San Matteo Foundation, Pavia, Italy. ${ }^{7}$ Emergency Medicine and Critical Care Consultant, King Fahad Specialist Hospital -Dammam, Dammam, Saudi Arabia. ${ }^{8}$ School of Medicine, Francisco de Vitoria University, Madrid, Spain. ${ }^{9}$ University of South Carolina School of Medicine, Columbia, SC, USA. ${ }^{10}$ Anesthesia and Intensive Care, Fondazione IRCCS Policlinico San Matteo, Università Degli Studi Di Pavia, Pavia, Italy. ${ }^{11}$ University Hospitals Cleveland Medical Center, Cleveland, $\mathrm{OH}$, USA. ${ }^{12}$ Service D'Anesthésie Réanimation Hôpital Nord, APHM, Chemin des Bourrely, 13015 Marseille, France. ${ }^{13}$ Department of Teaching and Research, Hospital "Dr. Emilio Ferreyra", Necochea, Argentina. ${ }^{14}$ Division of General Internal Medicine, Department of Medicine, University of Calgary, Calgary, Canada. ${ }^{15}$ Emergency and Trauma Department, Hospital Kuala Lumpur, 50586 Kuala Lumpur, Malaysia. ${ }^{16}$ King Abdulaziz Medical City, King Abdullah International Medical Research Center, Ministry of National Guard Health Affairs, Riyadh, Saudi Arabia. ${ }^{17}$ College of Public Health and Health Informatics, King Saud Bin Abdulaziz University for Health Sciences, Riyadh, Saudi Arabia. ${ }^{18}$ Dept of Anaesthesiology and Intensive Care, First Medical Faculty, Charles University, Prague, Czechia. ${ }^{19}$ Médico Ecografista IADT, Buenos Aires, Argentina. ${ }^{20}$ Intensive Care Division, Geneva University Hospitals, Geneva, Switzerland. ${ }^{21}$ Department of Anaesthesiology and Intensive Care, C.H.U. Dijon and Université Bourgogne Franche-Comté, LNC UMR866, 21000 Dijon, France. ${ }^{22}$ PICU Hospital San Juan de Dios, Santiago, Chile. ${ }^{23}$ FOM University of Economy \& Management, Frankfurt Campus, Frankfurt, Germany. ${ }^{24}$ Hospital General, Instituto Mexicano del Seguro Social, De Zona 4 Monterrey, Nuevo Leon, Mexico. ${ }^{25}$ Great North Trauma and Emergency Care Newcastle, Newcastle upon Tyne, UK. ${ }^{26}$ Emergency Department, Latisana General Hospital, Latisana, Italy. ${ }^{27}$ Department of Surgical, Medical and Molecular Pathology and Critical Care Medicine, University of Pisa, Pisa, Italy. ${ }^{28}$ University of Pennsylvania, Philadelphia, PA, USA. ${ }^{29}$ Montreal Heart Institute, Montreal, Canada. ${ }^{30}$ Medanta, The Medicity, Gurgaon, India. ${ }^{31}$ Ospedale Niguarda C'Grande, Milan, Italy. ${ }^{32}$ Dept. of Emergency Medicine, Bundang Jesaeng Hospital, Seoul, Korea. ${ }^{33}$ WINFOCUS Argentina BOD, Rosario, Argentina. ${ }^{34}$ Department of Clinical Laboratory Medicine and Department of Emergency Medicine, Jichi Medical University, Tokyo, Japan. ${ }^{35}$ Oregon Health and Science University, Portland, OR, USA. ${ }^{36}$ Department of Respiratory Medicine, Department 
of Clinical Research, Odense University Hospital, University of Southern Denmark, Odense, Denmark. ${ }^{37}$ Khoo Teck Puat Hospital, Singapore, Singapore. ${ }^{38}$ Dept. of Emergency Medicine, Yale School of Medicine, New Haven, CT, USA. ${ }^{39}$ Herzzentrum Leipzig, Leipzig, Germany. ${ }^{40}$ Department of Ultrasound \& Doppler Hospital de Emergencias "Dr. Clemente Alvarez", Rosario, Santa Fe, Argentina. ${ }^{41}$ Department of Emergency Medicine, Careggi University Hospital, Firenze, Italia. ${ }^{42}$ Department of Emergency Medicine, Icahn School of Medicine At Mount Sinai, New York, NY, USA. ${ }^{43}$ Clinical Hospital Zemun, Faculty of Medicine, University of Belgrade, Belgrade, Serbia. ${ }^{44}$ Faculty of Medecine, University of Lleida, Lleida, Spain. ${ }^{45}$ Hospital Raja Permaisuri Bainun, Ipoh, Perak, Malaysia. ${ }^{46}$ FAME - Medicine School of Barbacena - MG-Brasil, Barbacena, Brazil. ${ }^{47}$ Arbo Education, Rio de Janeiro, Brazil. ${ }^{48}$ SAMU 93 - Hôpital Avicenne, Paris, France. ${ }^{49}$ Città Della Salute E Della Scienza Di Torino Hospital, University of Turin, Turin, Italy. ${ }^{50}$ Faculty of Medicine and Pharmacy VUB, Univ Hospital Brussels, Brussels, Belgium. ${ }^{51}$ Royal Brompton Hospital, London, UK. ${ }^{52}$ Emergency Department, University Clinical Centre Maribor, Maribor, Slovenia. ${ }^{53}$ Hospital Nacional Edgardo Rebagliati Martins, Lima, Peru. ${ }^{54}$ Santa Cabrini Hospital, Montreal, Canada. ${ }^{55}$ Department of Surgery, The University of Melbourne, Melbourne, VIC, Australia. ${ }^{56}$ Outcomes Research Consortium, Cleveland Clinic, Cleveland, OH, USA. ${ }^{57}$ Department of Emergency Medicine, Hospital Universitario La Paz, Madrid, Spain. ${ }^{58}$ Division of Emergency Medicine, University of the Witwatersrand, Johannesburg, South Africa. ${ }^{59}$ King's College Hospital, London, UK. ${ }^{60}$ Department of Critical Care Medicine, Peking Union Medical College Hospital, Chinese Academy of Medical Sciences \& Peking Union Medical College, Beijing 100730, China. ${ }^{61}$ The Fourth Military Medical University, Xi'an 710032, China. ${ }^{62}$ King Abdulaziz Medical City, King Saud Bin Abdulaziz University for Health Sciences, King Abdullah International Medical Research Center, Riyadh, Saudi Arabia.

Received: 29 April 2020 Accepted: 3 November 2020 Published online: 24 December 2020

\section{References}

1. Coronavirus disease 2019 (COVID-19) Situation Report - 92 [https ://www.who.int/docs/default-source/coronaviruse/situation-repor ts/20200801-covid-19-sitrep-194.pdf?sfvrsn=401287f3_2]

2. Wu Z, McGoogan JM. Characteristics of and Important Lessons From the Coronavirus Disease 2019 (COVID-19) Outbreak in China: Summary of a Report of 72314 Cases From the Chinese Center for Disease Control and Prevention. JAMA 2020.

3. Mojoli F, Mongodi S, Orlando A, Arisi E, Pozzi M, Civardi L, Tavazzi G, Baldanti F, Bruno R, lotti GA, et al. Our recommendations for acute management of COVID-19. Crit Care. 2020;24(1):207.

4. Alhazzani W, Moller MH, Arabi YM, Loeb M, Gong MN, Fan E, Oczkowski S, Levy MM, Derde L, Dzierba A et al. Surviving Sepsis Campaign: Guidelines on the Management of Critically III Adults with Coronavirus Disease 2019 (COVID-19). Crit Care Med 2020.

5. Clinical management of severe acute respiratory infection when COVID-19 is suspected - Interim guidance. https://www.who.int/publi cations-detail/clinical-management-of-severe-acute-respiratory-infec tion-when-novel-coronavirus-(ncov)-infection-is-suspected.

6. Moore CL, Copel JA. Point-of-care ultrasonography. N Engl J Med. 2011;364(8):749-57.

7. Grasselli G, Pesenti A, Cecconi M. Critical care utilization for the COVID19 outbreak in lombardy. Italy: Early Experience and Forecast During an Emergency Response. JAMA; 2020.

8. Chen X, Tang Y, Mo Y, Li S, Lin D, Yang Z, Yang Z, Sun H, Qiu J, Liao Y et al. A diagnostic model for coronavirus disease 2019 (COVID-19) based on radiological semantic and clinical features: a multi-center study. Eur Radiol 2020

9. Grasselli G, Zangrillo A, Zanella A, Antonelli M, Cabrini L, Castelli A, Cereda D, Coluccello A, Foti G, Fumagalli R et al. Baseline characteristics and outcomes of 1591 patients infected With SARS-CoV-2 admitted to ICUs of the lombardy region, Italy. JAMA 2020.

10. Li Y, Yao L, Li J, Chen L, Song Y, Cai Z, Yang C. Stability issues of RT-PCR testing of SARS-CoV-2 for hospitalized patients clinically diagnosed with COVID-19. J Med Virol 2020.

11. Abrams ER, Rose G, Fields JM, Esener D. Point-of-Care Ultrasound in the Evaluation of COVID-19. J Emerg Med 2020.
12. Volpicelli G, Lamorte A, Villén T. What's new in lung ultrasound during the COVID-19 pandemic. Intensive Care Med. 2020;46:1445-8.

13. Antunez-Montes OY, Buonsenso D. Routine use of Point-of-Care lung ultrasound during the COVID-19 pandemic. Med Intensiva 2020.

14. Bhoi S, Sahu AK, Mathew R, Sinha TP. Point-of-care ultrasound in COVID19 pandemic. Postgrad Med J 2020.

15. Dong D, Tang Z, Wang S, Hui H, Gong L, Lu Y, Xue Z, Liao H, Chen F, Yang $F$ et al. The role of imaging in the detection and management of COVID-19: a review. IEEE Rev Biomed Eng 2020, PP.

16. Duggan N, Liteplo AS, Shokoohi A, Goldsmith AJ. Using lung pointof-care ultrasound in suspected COVID-19: case series and proposed triage algorithm. Clin Pract Cases Emerg Med 2020:289-294.

17. Guarracino F, Vetrugno L, Forfori F, Corradi F, Orso D, Bertini P, Ortalda A, Federici N, Copetti R, Bove T. Lung, heart, vascular, and diaphragm ultrasound examination of COVID-19 patients: a comprehensive approach. J Cardiothorac Vasc Anesth 2020

18. Piliego C, Strumia A, Stone MB, Pascarella G. The ultrasound guided triage: a new tool for prehospital management of COVID-19 pandemic. Anesth Analg 2020.

19. Erika P, Andrea V, Cillis MG, Ioannilli E, lannicelli T, Andrea M. Triage decision-making at the time of COVID-19 infection: the Piacenza strategy. Intern Emerg Med. 2020;15(5):879-82.

20. Smargiassi A, Soldati G, Borghetti A, Scoppettuolo G, Tamburrini E, Testa AC, Moro F, Natale L, Larici AR, Buonsenso D et al. Lung ultrasonography for early management of patients with respiratory symptoms during COVID-19 pandemic. J Ultrasound 2020.

21. Tierney DM, Huelster JS, Overgaard JD, Plunkett MB, Boland LL, St Hill CA, Agboto VK, Smith CS, Mikel BF, Weise BE, et al. Comparative performance of pulmonary ultrasound, chest radiograph, and CT among patients with acute respiratory failure. Crit Care Med. 2020;48(2):151-7.

22. Volpicelli G, Elbarbary M, Blaivas M, Lichtenstein DA, Mathis G, Kirkpatrick AW, Melniker L, Gargani L, Noble VE, Via G, et al. International evidence-based recommendations for point-of-care lung ultrasound. Intensive Care Med. 2012;38(4):577-91.

23. Ye X, Xiao H, Chen B, Zhang S. Accuracy of lung ultrasonography versus chest radiography for the diagnosis of adult community-acquired pneumonia: review of the literature and meta-analysis. PLOS ONE. 2015;10(6):e0130066.

24. Pare JR, Camelo I, Mayo KC, Leo MM, Dugas JN, Nelson KP, Baker WE, Shareef F, Mitchell PM, Schechter-Perkins EM. Point-of-care Lung Ultrasound Is More Sensitive than Chest Radiograph for Evaluation of COVID-19. West J Emerg Med. 2020;21(4):771-8.

25. Pivetta E, Goffi A, Lupia E, Tizzani M, Porrino G, Ferreri E, Volpicelli G, Balzaretti P, Banderali A, lacobucci A, et al. Lung ultrasound-implemented diagnosis of acute decompensated heart failure in the ED: A SIMEU multicenter study. Chest. 2015;148(1):202-10.

26. Laursen CB, Sloth E, Lassen AT, Christensen R, Lambrechtsen J, Madsen PH, Henriksen DP, Davidsen JR, Rasmussen F. Point-of-care ultrasonography in patients admitted with respiratory symptoms: a single-blind, randomised controlled trial. Lancet Respir Med. 2014;2(8):638-46.

27. Hankins A, Bang H, Walsh P. Point of care lung ultrasound is useful when screening for CoVid-19 in Emergency Department patients. medRxiv 2020.

28. Tan G, Lian X, Zhu Z, Wang Z, Huang F, Zhang Y, Zhao Y, He S, Wang $X$, Shen $\mathrm{H}$ et al. Use of Lung Ultrasound to Differentiate Coronavirus Disease 2019 (COVID-19) Pneumonia From Community-Acquired Pneumonia. Ultrasound Med Biol 2020.

29. Peng QY, Wang XT, Zhang LN, Chinese Critical Care Ultrasound Study G. Findings of lung ultrasonography of novel corona virus pneumonia during the 2019-2020 epidemic. Intensive Care Med 2020.

30. Soldati G, Smargiassi A, Inchingolo R, Buonsenso D, Perrone T, Briganti DF, Perlini S, Torri E, Mariani A, Mossolani EE et al. Proposal for international standardization of the use of lung ultrasound for COVID-19 patients; a simple, quantitative, reproducible method. J Ultrasound Med 2020.

31. Volpicelli G, Gargani L. Sonographic signs and patterns of COVID-19 pneumonia. Ultrasound J. 2020;12(1):22.

32. Soldati G, Smargiassi A, Inchingolo R, Buonsenso D, Perrone T, Briganti DF, Perlini S, Torri E, Mariani A, Mossolani EE et al. Is there a role for lung ultrasound during the COVID-19 pandemic? J Ultrasound Med 2020. 
33. Nouvenne A, Zani MD, Milanese G, Parise A, Baciarello M, Bignami EG, Odone A, Sverzellati N, Meschi T, Ticinesi A. Lung ultrasound in COVID19 pneumonia: correlations with chest CT on hospital admission. Respiration 2020:1-8.

34. Zieleskiewicz L, Markarian T, Lopez A, Taguet C, Mohammedi N, Boucekine M, Baumstarck K, Besch G, Mathon G, Duclos G et al. Comparative study of lung ultrasound and chest computed tomography scan in the assessment of severity of confirmed COVID-19 pneumonia. Intensive Care Med 2020.

35. Bonadia NC, Piano A, Buonsenso D, Gilardi E, Kadhim C, Torelli E, Petrucci M, Di Maurizio L, Biasucci DG, Fuorlo M, Forte E, Zaccaria R, Franceschi F. Lung ultrasound findings are associated with mortality and need of intensive care admission in COVID-19 patients evaluated in the Emergency Department. Ultrasound Med Biol 2020.

36. Lichter Y, Topilsky Y, Taieb P, Banai A, Hochstadt A, Merdler I, Gal Oz A, Vine J, Goren O, Cohen B et al. Lung ultrasound predicts clinical course and outcomes in COVID-19 patients. Intensive Care Med 2020.

37. Bar S, Lecourtois A, Diouf M, Goldberg E, Bourbon C, Arnaud E, Domisse $L$, Dupont $H$, Gosset P. The association of lung ultrasound images with COVID-19 infection in an emergency room cohort. Anaesthesia 2020.

38. Benchoufi MBJ, Chauvin A, Dion E, Baranne ML, Levan F, Vicaut E, Bourrier P. Lung injury in patients with or suspected COVID-19: a comparison between lung ultrasound and chest CT-scanner severity assessments, an observational study. In: medRxiv preprint. 2020.

39. Peyrony O, Marbeuf-Gueye C, Truong V, Giroud M, Riviere C, Khenissi K, Legay L, Simonetta M, Elezi A, Principe A et al. Accuracy of Emergency Department Clinical Findings for Diagnosis of Coronavirus Disease 2019. Ann Emerg Med 2020

40. Tung Chen YLFR, Rodriguez Fuertes $P$. The role of point-of care ultrasonography in the initial characterization of COVID-19 patients: Results from a prospective multicentric study. medRxiv 2020

41. Llamas-Alvarez AM, Tenza-Lozano EM, Latour-Perez J. Accuracy of lung ultrasonography in the diagnosis of pneumonia in adults: systematic review and meta-analysis. Chest. 2017;151(2):374-82.

42. Bataille B, Riu B, Ferre F, Moussot PE, Mari A, Brunel E, Ruiz J, Mora M, Fourcade $\mathrm{O}$, Genestal $M$, et al. Integrated use of bedside lung ultrasound and echocardiography in acute respiratory failure: a prospective observational study in ICU. Chest. 2014;146(6):1586-93.

43. Kajimoto K, Madeen K, Nakayama T, Tsudo H, Kuroda T, Abe T. Rapid evaluation by lung-cardiac-inferior vena cava (LCI) integrated ultrasound for differentiating heart failure from pulmonary disease as the cause of acute dyspnea in the emergency setting. Cardiovasc Ultrasound. 2012;10(1):49.

44. Nazerian P, Vanni S, Volpicelli G, Gigli C, Zanobetti M, Bartolucci M, Ciavattone A, Lamorte A, Veltri A, Fabbri A, et al. Accuracy of point-of-care multiorgan ultrasonography for the diagnosis of pulmonary embolism. Chest. 2014;145(5):950-7.

45. Zanobetti M, Scorpiniti M, Gigli C, Nazerian P, Vanni S, Innocenti F, Stefanone VT, Savinelli C, Coppa A, Bigiarini S, et al. Point-of-care ultrasonography for evaluation of acute dyspnea in the ED. Chest. 2017;151(6):1295-301.

46. Volpicelli G, Lamorte A, Tullio M, Cardinale L, Giraudo M, Stefanone V, Boero E, Nazerian P, Pozzi R, Frascisco MF. Point-of-care multiorgan ultrasonography for the evaluation of undifferentiated hypotension in the emergency department. Intensive Care Med. 2013;39(7):1290-8.

47. Via G, Hussain A, Wells M, Reardon R, ElBarbary M, Noble VE, Tsung JW, Neskovic AN, Price S, Oren-Grinberg A et al: International evidencebased recommendations for focused cardiac ultrasound. J Am Soc Echocardiogr 2014, 27(7):683 e681-683 e633.

48. McInnes MDF, Leeflang MMG, Salameh JP, McGrath TA, van der Pol CB, Frank RA, Prager R, Hare SS. Dennie C. Imaging tests for the diagnosis of COVID-19 (Protocol). In: Cochrane Library. Wiley; 2020.

49. Zheng YY, Ma YT, Zhang JY, Xie X. COVID-19 and the cardiovascular system. Nat Rev Cardiol 2020.

50. Thygesen K, Alpert JS, Jaffe AS, Chaitman BR, Bax JJ, Morrow DA, White HD. Executive group on behalf of the joint european society of cardiology/American college of cardiology/American heart association/world heart federation task force for the universal definition of myocardial i: fourth universal definition of myocardial infarction (2018). Circulation. 2018;138(20):e618-51.
51. Wang D, Hu B, Hu C, Zhu F, Liu X, Zhang J, Wang B, Xiang H, Cheng Z, Xiong $Y$ et al. Clinical characteristics of 138 hospitalized patients with 2019 novel coronavirus-infected pneumonia in Wuhan, China. JAMA 2020.

52. Huang C, Wang Y, Li X, Ren L, Zhao J, Hu Y, Zhang L, Fan G, Xu J, Gu X, et al. Clinical features of patients infected with 2019 novel coronavirus in Wuhan China. Lancet. 2020;395(10223):497-506.

53. Shi S, Qin M, Shen B, Cai Y, Liu T, Yang F, Gong W, Liu X, Liang J, Zhao $Q$ et al. Association of Cardiac Injury With Mortality in Hospitalized Patients With COVID-19 in Wuhan, China. JAMA Cardiol 2020

54. Thygesen K, Alpert JS, Jaffe AS, Chaitman BR, Bax JJ, Morrow DA, White HD, Thygesen K, Alpert JS, Jaffe AS, et al. Fourth universal definition of myocardial infarction (2018). Eur Heart J. 2019;40(3):237-69.

55. Kociol RD, Cooper LT, Fang JC, Moslehi JJ, Pang PS, Sabe MA, Shah RV, Sims DB, Thiene G, Vardeny O, et al. Recognition and initial management of fulminant myocarditis: a scientific statement from the american heart association. Circulation. 2020;141(6):e69-92.

56. McCarthy CP, Raber I, Chapman AR, Sandoval Y, Apple FS, Mills NL Januzzi $J \mathrm{~L}$, Jr. Myocardial injury in the era of high-sensitivity cardiac troponin assays: a practical approach for clinicians. JAMA Cardiol 2019.

57. Churchill TW, Bertrand PB, Bernard S, Namasivayam M, Churchill J, Crousillat D, Davis EF, Hung J, Picard MH. Echocardiographic features of COVID-19 illness and association with cardiac biomarkers. J Am Soc Echocardiogr. 2020;33(8):1053-4.

58. Dweck MR, Bularga A, Hahn RT, Bing R, Lee KK, Chapman AR, White A, Salvo GD, Sade LE, Pearce K et al. Global evaluation of echocardiography in patients with COVID-19. Eur Heart J Cardiovasc Imaging 2020.

59. Fried JA, Ramasubbu K, Bhatt R, Topkara VK, Clerkin KJ, Horn E, Rabbani $L$, Brodie D, Jain SS, Kirtane A et al. The variety of cardiovascular presentations of COVID-19. Circulation 2020.

60. Price LC, MCAuley DF, Marino PS, Finney SJ, Griffiths MJ, Wort SJ. Pathophysiology of pulmonary hypertension in acute lung injury. Am J Physiol Lung Cell Mol Physiol. 2012;302(9):L803-815.

61. Repesse X, Charron C, Vieillard-Baron A. Acute cor pulmonale in ARDS: rationale for protecting the right ventricle. Chest. 2015;147(1):259-65.

62. Clerkin KJ, Fried JA, Raikhelkar J, Sayer G, Griffin JM, Masoumi A, Jain SS, Burkhoff D, Kumaraiah D, Rabbani L, et al. COVID-19 and cardiovascular disease. Circulation. 2020;141(20):1648-55

63. Cecconi M, De Backer D, Antonelli M, Beale R, Bakker J, Hofer C, Jaeschke R, Mebazaa A, Pinsky MR, Teboul JL et al: Consensus on circulatory shock and hemodynamic monitoring. Task force of the European Society of Intensive Care Medicine. Intensive Care Med 2014, 40(12):1795-1815.

64. Price S, Platz E, Cullen L, Tavazzi G, Christ M, Cowie MR, Maisel AS, Masip J, Miro O, McMurray JJ, et al. Expert consensus document: Echocardiography and lung ultrasonography for the assessment and management of acute heart failure. Nat Rev Cardiol. 2017;14(7):427-40.

65. Jain SS LQ, Raikhelkar J, Fried J, Elias P, Poterucha TJ, DeFilippis EM, Rosenblum H, Wang EY, Redfors B, Clerkin K, Griffin JM, Wan EY, Abdalla M, Bello NA, Hahn RT, Shimbo D, Weiner SD, Kirtane AJ, Kodali SK, Burkhoff D, Rabbani LE, Schwartz A, Leon MB, Homma S, Di Tullio MR, Sayer G, Uriel N, Anstey DE. Indications for and findings on transthoracic echocardiography in COVID-19. J Am Soc Echocardigr 2020.

66. Johry AGB, Kirkpatrick JN, Lanspa M, Mulvagh S, Thamman R. ASE Statement on point-of-care ultrasound (PoCUS) during the 2019 novel coronavirus pandemic. J Am Soc Echocardigr 2020, in press.

67. Cosyns B, Lochy S, Luchian ML, Gimelli A, Pontone G, Allard SD, de Mey J, Rosseel P, Dweck M, Petersen SE, et al. The role of cardiovascular imaging for myocardial injury in hospitalized COVID-19 patients. Eur Heart J Cardiovasc Imaging. 2020;21(7):709-14.

68. Zeng J, Huang J, Pan L. How to balance acute myocardial infarction and COVID-19: the protocols from Sichuan Provincial People's Hospital. Intensive Care Med 2020.

69. Vignon P, Begot E, Mari A, Silva S, Chimot L, Delour P, Vargas F, Filloux B, Vandroux D, Jabot J, et al. Hemodynamic assessment of patients with septic shock using transpulmonary thermodilution and critical care echocardiography: a comparative study. Chest. 2018;153(1):55-64.

70. van Diepen S, Katz JN, Albert NM, Henry TD, Jacobs AK, Kapur NK, Kilic A, Menon V, Ohman EM, Sweitzer NK, et al. Contemporary management of cardiogenic shock: a scientific statement from the american heart association. Circulation. 2017;136(16):e232-68. 
71. Skouri HN, Dec GW, Friedrich MG, Cooper LT. Noninvasive imaging in myocarditis. J Am Coll Cardiol. 2006;48(10):2085-93.

72. Szekely Y, Lichter Y, Taieb P, Banai A, Hochstadt A, Merdler I, Gal Oz A, Rothschild E, Baruch G, Peri Y, et al. Spectrum of cardiac manifestations in COVID-19: a systematic echocardiographic study. Circulation. 2020;142(4):342-53.

73. Tavazzi GCL, Caneva L, Mongodi S, Mojoli F. Thrombotic events in SARSCov 2 patients: an urgent call for ultrasound screening. Intensive Care Med 2020.

74. Ren B, Yan F, Deng Z, Zhang S, Xiao L, Wu M, Cai L. Extremely high incidence of lower extremity deep venous thrombosis in 48 patients with severe COVID-19 in Wuhan. Circulation. 2020;142(2):181-3.

75. Helms J, Tacquard J, Severac F, Lorant J, Ohana M, Delabranche X, AL. E, Sepsis) aftCTGCRilCaSTGfGEaRi: High risk of thrombosis in patients in severe SARS-CoV-2 infection: a multicenter prospective cohort study. Intensive Care Med 2020, in press.

76. Klok FA, Kruip M, van der Meer NJM, Arbous MS, Gommers D, Kant KM, Kaptein FHJ, van Paassen J, Stals MAM, Huisman MV et al. Incidence of thrombotic complications in critically ill ICU patients with COVID-19. Thromb Res 2020

77. Frantzeskaki F, Armaganidis A, Orfanos SE. Immunothrombosis in acute respiratory distress syndrome: cross talks between inflammation and coagulation. Respiration. 2017;93(3):212-25.

78. Zhou F, Yu T, Du R, Fan G, Liu Y, Liu Z, Xiang J, Wang Y, Song B, Gu X, et al. Clinical course and risk factors for mortality of adult inpatients with COVID-19 in Wuhan, China: a retrospective cohort study. Lancet. 2020;395(10229):1054-62.

79. Tang N, Bai H, Chen X, Gong J, Li D, Sun Z. Anticoagulant treatment is associated with decreased mortality in severe coronavirus disease 2019 patients with coagulopathy. J Thromb Haemost 2020.

80. Thachil JTN, Gando S, Falanga A, Cattaneo M, Levi M, Clark C, Iba T. ISTH interim guidance on recognition and management of coagulopathy in COVID-19. Thromb Haemosth 2020, in press.

81. Demelo-Rodriguez P, Cervilla-Munoz E, Ordieres-Ortega L, Parra-Virto A, Toledano-Macias M, Toledo-Samaniego N, Garcia-Garcia A, GarciaFernandez-Bravo I, Ji Z, de-Miguel-Diez J et al. Incidence of asymptomatic deep vein thrombosis in patients with COVID-19 pneumonia and elevated D-dimer levels. Thromb Res 2020, 192:23-26.

82. Trimaille A, Curtiaud A, Marchandot B, Matsushita K, Sato C, LeonardLorant I, Sattler L, Grunebaum L, Ohana M, Von Hunolstein JJ, et al. Venous thromboembolism in non-critically ill patients with COVID-19 infection. Thromb Res. 2020;193:166-9.

83. Blaivas M. Ultrasound in the detection of venous thromboembolism. Crit Care Med. 2007;35(5 Suppl):S224-234.

84. Marietta M, Ageno W, Artoni A, De Candia E, Gresele P, Marchetti M, Marcucci R, Tripodi A. COVID-19 and haemostasis: a position paper from Italian Society on Thrombosis and Haemostasis (SISET). Blood Transfus 2020

85. Obi AT, Barnes GD, Wakefield TW, Brown Rvt S, Eliason JL, Arndt E, Henke PK. Practical diagnosis and treatment of suspected venous thromboembolism during COVID-19 Pandemic. J Vasc Surg Venous Lymphat Disord 2020.

86. Moores LK, Tritschler T, Brosnahan S, Carrier M, Collen JF, Doerschug K, Holley AB, Jimenez D, Le Gal G, Rali P et al. Prevention, Diagnosis, and Treatment of VTE in Patients With Coronavirus Disease 2019: CHEST Guideline and Expert Panel Report. Chest 2020

87. Arabi YM, Burns KEA, Alsolamy SJ, Alshahrani MS, Al-Hameed FM, Arshad Z, Almaani M, Hawa H, Mandourah Y, Almekhlafi GA, et al. Surveillance or no surveillance ultrasonography for deep vein thrombosis and outcomes of critically ill patients: a pre-planned sub-study of the PREVENT trial. Intensive Care Med. 2020;46(4):737-46.

88. Marini JJ, Dellinger RP, Brodie D. Integrating the evidence: confronting the COVID-19 elephant. Intensive Care Med 2020.

89. Gattinoni LCD, Caironi P, Busana M, Romitti F, Brazzi L, Camporota L. COVID-19 pneumonia: different respiratory treatment for different phenotypes? Intensive Care Med 2020.

90. Gattinoni L, Caironi P, Pelosi P, Goodman LR. What has computed tomography taught us about the acute respiratory distress syndrome? Am J Respir Crit Care Med. 2001;164(9):1701-11.
91. Wang Y, Dong C, Hu Y, Li C, Ren Q, Zhang X, Shi H, Zhou M. Temporal Changes of CT Findings in 90 Patients with COVID-19 Pneumonia: A Longitudinal Study. Radiology 2020:200843.

92. Rouby JJ, Puybasset L, Nieszkowska A, Lu Q. Acute respiratory distress syndrome: lessons from computed tomography of the whole lung. Crit Care Med. 2003;31(4 Suppl):S285-295.

93. Elharrar X, Trigui Y, Dols AM, Touchon F, Martinez S, Prud'homme E, Papazian L: Use of Prone Positioning in Nonintubated Patients With COVID-19 and Hypoxemic Acute Respiratory Failure. JAMA 2020.

94. Coppo A, Bellani G, Winterton D, Di Pierro M, Soria A, Faverio P, Cairo M, Mori S, Messinesi G, Contro E, et al. Feasibility and physiological effects of prone positioning in non-intubated patients with acute respiratory failure due to COVID-19 (PRON-COVID): a prospective cohort study. Lancet Respir Med. 2020;8(8):765-74.

95. Chiumello D, Umbrello M, Sferrazza Papa GF, Angileri A, Gurgitano M, Formenti P, Coppola S, Froio S, Cammaroto A, Carrafiello G. Global and Regional Diagnostic Accuracy of Lung Ultrasound Compared to CT in Patients With Acute Respiratory Distress Syndrome. Crit Care Med. 2019;47(11):1599-606.

96. Denault AY, Delisle S, Canty D, Royse A, Royse C, Serra XC, Gebhard CE, Couture EJ, Girard M, Cavayas YA et al. A proposed lung ultrasound and phenotypic algorithm for the care of COVID-19 patients with acute respiratory failure. Can J Anaesth 2020.

97. Chiumello D, Mongodi S, Algieri I, Vergani GL, Orlando A, Via G, Crimella F, Cressoni M, Mojoli F. Assessment of lung aeration and recruitment by $\mathrm{CT}$ scan and ultrasound in acute respiratory distress syndrome patients. Crit Care Med. 2018:46(11):1761-8.

98. Bouhemad B, Mongodi S, Via G, Rouquette I. Ultrasound for "lung monitoring" of ventilated patients. Anesthesiology. 2015;122(2):437-47.

99. Bouhemad B, Brisson H, Le-Guen M, Arbelot C, Lu Q, Rouby JJ. Bedside ultrasound assessment of positive end-expiratory pressure-induced lung recruitment. Am J Respir Crit Care Med. 2011;183(3):341-7.

100. Haddam M, Zieleskiewicz L, Perbet S, Baldovini A, Guervilly C, Arbelot C, Noel A, Vigne C, Hammad E, Antonini F, et al. Lung ultrasonography for assessment of oxygenation response to prone position ventilation in ARDS. Intensive Care Med. 2016;42(10):1546-56.

101. Zhao Z, Jiang L, Xi X, Jiang $Q$, Zhu B, Wang $M$, Xing J, Zhang D. Prognostic value of extravascular lung water assessed with lung ultrasound score by chest sonography in patients with acute respiratory distress syndrome. BMC Pulm Med. 2015;15:98.

102. Bataille B, Rao G, Cocquet P, Mora M, Masson B, Ginot J, Silva S, Moussot PE. Accuracy of ultrasound B-lines score and E/Ea ratio to estimate extravascular lung water and its variations in patients with acute respiratory distress syndrome. J Clin Monit Comput. 2015;29(1):169-76.

103. Via G, Lichtenstein D, Mojoli F, Rodi G, Neri L, Storti E, Klersy C, lotti G, Braschi A. Whole lung lavage: a unique model for ultrasound assessment of lung aeration changes. Intensive Care Med. 2010;36(6):999-1007.

104. Dargent A, Chatelain E, Kreitmann L, Quenot JP, Cour M, Argaud L. group C-Ls. Lung ultrasound score to monitor COVID-19 pneumonia progression in patients with ARDS. PLoS ONE. 2020;15(7):e0236312.

105. Deng $Q$, Zhang Y, Wang H, Chen L, Yang Z, Peng Z, Liu Y, Feng C, Huang $X$, Jiang $N$ et al. Semiquantitative lung ultrasound scores in the evaluation and follow-up of critically ill patients with COVID-19: a singlecenter study. Acad Radiol 2020.

106. Moller-Sorensen H, Gjedsted J, Lind Jorgensen V, Lindskov Hansen K. COVID-19 Assessment with Bedside Lung Ultrasound in a Population of Intensive Care Patients Treated with Mechanical Ventilation and ECMO. Diagnostics (Basel) 2020, 10(7).

107. Marik PE, Linde-Zwirble WT, Bittner EA, Sahatjian J, Hansell D. Fluid administration in severe sepsis and septic shock, patterns and outcomes: an analysis of a large national database. Intensive Care Med. 2017:43(5):625-32.

108. Michard FM, Martin GS, Fumeaux T, Lobo S, Gonzalez F, Pinho-Oliveira V, Constantin JM. Haemodynamic Monitoring and Management in COVID-19 Intensive Care Patients/ An International Survey. Anaesthesia Critical Care \& Pain Medicine 2020.

109. Via G, Tavazzi G, Price S. Ten situations where inferior vena cava ultrasound may fail to accurately predict fluid responsiveness: a physiologically based point of view. Intensive Care Med. 2016;42(7):1164-7. 
110. ASE Statement on Protection of Patients and Echocardiography Service Providers During the 2019 Novel Coronavirus Outbreak [https://www. asecho.org/wp-content/uploads/2020/03/COVIDStatementFINAL4 -1-2020_v2_website.pdf]

111. Boyd JH, Sirounis D, Maizel J, Slama M. Echocardiography as a guide for fluid management. Crit Care. 2016;20:274.

112. Monnet X, Marik PE, Teboul JL. Prediction of fluid responsiveness: an update. Ann Intensive Care. 2016;6(1):111.

113. Nair S, Sauthoff H: Assessing extravascular lung water with ultrasound: a tool to individualize fluid management? J Intensive Care Med 2019:885066619855000.

114. Caltabeloti F, Monsel A, Arbelot C, Brisson H, Lu Q, Gu WJ, Zhou GJ, Auler JO, Rouby JJ. Early fluid loading in acute respiratory distress syndrome with septic shock deteriorates lung aeration without impairing arterial oxygenation: a lung ultrasound observational study. Crit Care. 2014;18(3):R91.

115. Trezzi M, Torzillo D, Ceriani E, Costantino G, Caruso S, Damavandi PT, Genderini A, Cicardi M, Montano N, Cogliati C. Lung ultrasonography for the assessment of rapid extravascular water variation: evidence from hemodialysis patients. Intern Emerg Med. 2013;8(5):409-15.

116. Reisinger N, Koratala A. Lung ultrasound: a valuable tool for the assessment of dialysis patients with COVID-19. Clin Exp Nephrol 2020.

117. Vieira ALS, Pazeli Junior JM, Bastos MG. Role of point-of-care ultrasound during the COVID-19 pandemic: our recommendations in the management of dialytic patients. Ultrasound J. 2020;12(1):30.

118. Guan WJ, Ni ZY, Hu Y, Liang WH, Ou CQ, He JX, Liu L, Shan H, Lei CL, Hui DSC et al. Clinical Characteristics of Coronavirus Disease 2019 in China. N Engl J Med 2020.

119. Xie J, Tong Z, Guan X, Du B, Qiu H, Slutsky AS. Critical care crisis and some recommendations during the COVID-19 epidemic in China. Intensive Care Med 2020.

120. Bouadma L, Lescure FX, Lucet JC, Yazdanpanah Y, Timsit JF. Severe SARSCoV-2 infections: practical considerations and management strategy for intensivists. Intensive Care Med 2020.

121. Mongodi S, Pozzi M, Orlando A, Bouhemad B, Stella A, Tavazzi G, Via G, lotti GA, Mojoli F. Lung ultrasound for daily monitoring of ARDS patients on extracorporeal membrane oxygenation: preliminary experience. Intensive Care Med. 2018:44(1):123-4.

122. Enghard $P$, Rademacher $S$, Nee J, Hasper D, Engert $U$, Jorres $A$, Kruse $J M$. Simplified lung ultrasound protocol shows excellent prediction of extravascular lung water in ventilated intensive care patients. Crit Care. 2015;19:36

123. Heldeweg MM, Haaksma ME, Smit JM, Kraemer CVE, Tuinman PR. Lung ultrasound and computed tomography to monitor COVID-19 pneumonia in critically ill patients/ a two-center prospective cohort study. In: RES SQUARE preprint. 2020.

124. Palmese F, Caroli B, Graziani A, Zanframundo G, Del Toro R, Sagrini E, Cataleta P, Domenicali M. Daily Evaluation of COVID-19 Patients Primarily Based on Lung Ultrasound: In Times of Emergency, It's Time to Change Some Paradigms. Am J Trop Med Hyg 2020, 103(2):922-923.

125. Shokoohi H, Duggan NM, Garcia-de-Casasola Sanchez G, TorresArrese $M$, Tung-Chen $Y$. Lung ultrasound monitoring in patients with COVID-19 on home isolation. Am J Emerg Med 2020.

126. Tung-Chen Y. Lung ultrasound in the monitoring of COVID-19 infection. Clin Med (Lond). 2020;20(4):e62-5.

127. Mongodi S, Via G, Girard M, Rouquette I, Misset B, Braschi A, Mojoli $F$, Bouhemad B. Lung ultrasound for early diagnosis of ventilatorassociated pneumonia. Chest. 2016;149(4):969-80.

128. Bouhemad B, Liu ZH, Arbelot C, Zhang M, Ferarri F, Le-Guen M, Girard $\mathrm{M}, \mathrm{Lu} \mathrm{Q}$, Rouby JJ. Ultrasound assessment of antibiotic-induced pulmonary reaeration in ventilator-associated pneumonia. Crit Care Med. 2010;38(1):84-92.

129. Peris A, Tutino L, Zagli G, Batacchi S, Cianchi G, Spina R, Bonizzoli M, Migliaccio L, Perretta L, Bartolini M, et al. The use of point-ofcare bedside lung ultrasound significantly reduces the number of radiographs and computed tomography scans in critically ill patients. Anesth Analg. 2010;111(3):687-92.

130. Mongodi S, Orlando A, Arisi E, Tavazzi G, Santangelo E, Caneva L, Pozzi M, Pariani E, Bettini G, Maggio G, et al. Lung ultrasound in patients with acute respiratory failure reduces conventional imaging and health care provider exposure to COVID-19. Ultrasound Med Biol. 2020;46(8):2090-3.

131. Alrajab S, Youssef AM, Akkus NI, Caldito G. Pleural ultrasonography versus chest radiography for the diagnosis of pneumothorax: review of the literature and meta-analysis. Crit Care. 2013;17(5):R208.

132. Volpicelli G. Sonographic diagnosis of pneumothorax. Intensive Care Med. 2011;37(2):224-32.

133. Mongodi S, Bouhmad B, Orlando A, Stella A, Via G, lotti G, Mojoli F. Lung ultrasound before and after fiberbronchoscopy - modifications may improve ventilator associated pneumonia diagnosis - in: Erratum to: 36 th International Symposium on Intensive Care and Emergency Medicine: Brussels, Belgium. 15-18 March 2016. Crit Care 2016, 20:347.

134. Zagli G, Cozzolino M, Terreni A, Biagioli T, Caldini AL, Peris A. Diagnosis of ventilator-associated pneumonia: a pilot, exploratory analysis of a new score based on procalcitonin and chest echography. Chest. 2014;146(6):1578-85.

135. Dres M, Goligher EC, Heunks LMA, Brochard LJ. Critical illness-associated diaphragm weakness. Intensive Care Med. 2017;43(10):1441-52.

136. Soummer A, Perbet S, Brisson H, Arbelot C, Constantin JM, Lu Q, Rouby JJ. Lung Ultrasound Study G: Ultrasound assessment of lung aeration loss during a successful weaning trial predicts postextubation distress*. Crit Care Med. 2012;40(7):2064-72.

137. Bouhemad B, Mojoli F, Nowobilski N, Hussain A, Rouquette I, Guinot PG, Mongodi S. Use of combined cardiac and lung ultrasound to predict weaning failure in elderly, high-risk cardiac patients: a pilot study. Intensive Care Med. 2020;46(3):475-84.

138. Li C, Li X, Han H, Cui H, Wang G, Wang Z. Diaphragmatic ultrasonography for predicting ventilator weaning: A meta-analysis. Medicine (Baltimore). 2018;97(22):e10968.

139. Silva S, Ait Aissa D, Cocquet $P$, Hoarau L, Ruiz J, Ferre F, Rousset $D$, Mora M, Mari A, Fourcade O, et al. Combined Thoracic Ultrasound Assessment during a Successful Weaning Trial Predicts Postextubation Distress. Anesthesiology. 2017;127(4):666-74.

140. Dres M, Dube BP, Goligher E, Vorona S, Demiri S, Morawiec E, Mayaux J, Brochard L, Similowski T, Demoule A. Usefulness of Parasternal Intercostal Muscle Ultrasound during Weaning from Mechanical Ventilation. Anesthesiology 2020.

141. Razazi K, Boissier F, Neuville M, Jochmans S, Tchir M, May F, de Prost N, Brun-Buisson C, Carteaux G, Mekontso Dessap A. Pleural effusion during weaning from mechanical ventilation: a prospective observational multicenter study. Ann Intensive Care. 2018;8(1):103.

142. Mekontso Dessap A, Roche-Campo F, Kouatchet A, Tomicic V, Beduneau G, Sonneville R, Cabello B, Jaber S, Azoulay E, CastanaresZapatero $D$, et al. Natriuretic peptide-driven fluid management during ventilator weaning: a randomized controlled trial. Am J Respir Crit Care Med. 2012;186(12):1256-63.

143. Gernoth C, Wagner G, Pelosi P, Luecke T. Respiratory and haemodynamic changes during decremental open lung positive end-expiratory pressure titration in patients with acute respiratory distress syndrome. Crit Care. 2009;13(2):R59.

144. Yang X, Yu Y, Xu J, Shu H, Xia J, Liu H, Wu Y, Zhang L, Yu Z, Fang M et al. Clinical course and outcomes of critically ill patients with SARSCoV-2 pneumonia in Wuhan, China: a single-centered, retrospective, observational study. Lancet Respir Med 2020.

145. Pan XW, Xu D, Zhang H, Zhou W, Wang LH, Cui XG. Identification of a potential mechanism of acute kidney injury during the COVID-19 outbreak: a study based on single-cell transcriptome analysis. Intensive Care Med 2020.

146. Chougar L, Shor N, Weiss N, Galanaud D, Leclercq D, Mathon B, Belkacem S, Stroer S, Burrel S, Boutolleau D et al. Retrospective Observational Study of Brain Magnetic Resonance Imaging Findings in Patients with Acute SARS-CoV-2 Infection and Neurological Manifestations. Radiology 2020:202422.

147. Barozzi L, Valentino M, Santoro A, Mancini E, Pavlica P. Renal ultrasonography in critically ill patients. Crit Care Med. 2007;35(5 Suppl):S198-205.

148. Beaubien-Souligny W RP, Haycock K, Bouchard J, Lamarche Y, Spiegel $R$, Denault AY. Quantifying systemic congestion with Point-Of-Care ultrasound: Development of the Venous Excess Ultrasound grading system. The Ultrasound Journal 2020, in press. 
149. Perez-Calatayud AA, Carrillo-Esper R, Anica-Malagon ED, Briones-Garduno JC, Arch-Tirado E, Wise R, Malbrain M. Point-of-care gastrointestinal and urinary tract sonography in daily evaluation of gastrointestinal dysfunction in critically ill patients (GUTS Protocol). Anaesthesiol Intensive Ther. 2018;50(1):40-8.

150. Hoffmann B, Nurnberg D, Westergaard MC. Focus on abnormal air: diagnostic ultrasonography for the acute abdomen. Eur J Emerg Med. 2012;19(5):284-91.

151. Bhayana R, Som A, Li MD, Carey DE, Anderson MA, Blake MA, Catalano O, Gee MS, Hahn PF, Harisinghani M et al: Abdominal Imaging Findings in COVID-19: Preliminary Observations. Radiology 2020:201908.

152. Robba C, Goffi A, Geeraerts T, Cardim D, Via G, Czosnyka M, Park S, Sarwal A, Padayachy L, Rasulo F, et al. Brain ultrasonography: methodology, basic and advanced principles and clinical applications A narrative review. Intensive Care Med. 2019;45(7):913-27.

153. McMahon SR, De Francis G, Schwartz S, Duvall WL, Arora B, Silverman DI. Tablet-based limited echocardiography to reduce sonographer scan and decontamination time during the COVID-19 Pandemic. J Am Soc Echocardiogr. 2020;33(7):895-9.

154. Bobbia X, Chabannon M, Chevallier T, de La Coussaye JE, Lefrant JY, Pujol S, Claret PG, Zieleskiewicz L, Roger C, Muller L. Assessment of five different probes for lung ultrasound in critically ill patients: A pilot study. Am J Emerg Med. 2018;36(7):1265-9.

155. Ye R, Zhou X, Shao F, Xiong L, Hong J, Huang H, Tong W, Wang J, Chen S, Cui A et al. Feasibility of a $5 \mathrm{G}$-based robot-assisted remote ultrasound system for cardiopulmonary assessment of COVID-19 patients. Chest 2020
156. Levine AR, McCurdy MT, Zubrow MT, Papali A, Mallemat HA, Verceles AC. Tele-intensivists can instruct non-physicians to acquire highquality ultrasound images. J Crit Care. 2015;30(5):871-5.

157. Britton N, Miller MA, Safadi S, Siegel A, Levine AR, McCurdy MT. Teleultrasound in resource-limited settings: a systematic review. Front Public Health. 2019;7:244.

158. Ma IW, Somayaji R, Rennert-May E, Minardi J, Walsh MH, Wiskar K, Smyth LM, Burgoyne S, Chan B, Haroon BA, Desy J. Canadian Internal Medicine Ultrasound (CIMUS) Recommendations Regarding Internal Medicine Point- of-Care Ultrasound (PoCUS) use during Coronavirus (COVID-19) pandemic. Canadian Journal of General Internal Medicine. 2020;15(2):8-11

159. Guidelines for Cleaning and Preparing External- and Internal-Use Ultrasound Transducers and Equipment Between Patients as well as Safe Handling and Use of Ultrasound Coupling Gel [https://www. aium.org/officialStatements/57]

160. van Doremalen N, Bushmaker T, Morris DH, Holbrook MG, Gamble A, Williamson BN, Tamin A, Harcourt JL, Thornburg NJ, Gerber Sl et al. Aerosol and Surface Stability of SARS-CoV-2 as Compared with SARSCoV-1. N Engl J Med 2020

\section{Publisher's Note}

Springer Nature remains neutral with regard to jurisdictional claims in published maps and institutional affiliations.
Ready to submit your research? Choose BMC and benefit from:

- fast, convenient online submission

- thorough peer review by experienced researchers in your field

- rapid publication on acceptance

- support for research data, including large and complex data types

- gold Open Access which fosters wider collaboration and increased citations

- maximum visibility for your research: over $100 \mathrm{M}$ website views per year

At BMC, research is always in progress.

Learn more biomedcentral.com/submissions 